\title{
TRPA1 Modulates Mechanotransduction in Cutaneous Sensory Neurons
}

\author{
Kelvin Y. Kwan, ${ }^{1,2 \star}$ Joshua M. Glazer, ${ }^{3 \star}$ David P. Corey, ${ }^{1,2}$ Frank L. Rice, ${ }^{4,5}$ and Cheryl L. Stucky ${ }^{3}$ \\ ${ }^{1}$ Department of Neurobiology and ${ }^{2}$ Howard Hughes Medical Institute, Harvard Medical School, Boston, Massachusetts 02115, ${ }^{3}$ Department of Cell Biology, \\ Neurobiology and Anatomy, Medical College of Wisconsin, Milwaukee, Wisconsin 53226, ${ }^{4}$ Center for Neuropharmacology and Neuroscience, Albany \\ Medical College, Albany, New York 12054, and ${ }^{5}$ Integrated Tissue Dynamics LLC, Renssalear, New York 12144
}

Transient receptor potential ankyrin 1 (TRPA1) is expressed by nociceptive neurons of the dorsal root ganglia (DRGs) and trigeminal ganglia, but its roles in cold and mechanotransduction are controversial. To determine the contribution of TRPA1 to cold and mechanotransduction in cutaneous primary afferent terminals, we used the ex vivo skin-nerve preparation from $\operatorname{Trpa1}^{+/+}, \operatorname{Trpa1}^{+/-}$, and Trpa1 $^{-1-}$ adult mouse littermates. Cutaneous fibers from TRPA1-deficient mice showed no deficits in acute cold sensitivity, but they displayed striking deficits in mechanical response properties. C-fiber nociceptors from $\operatorname{Trpa1}^{-1-}$ mice exhibited action potential firing rates $50 \%$ lower than those in wild-type $\mathrm{C}$-fibers across a wide range of force intensities. $\mathrm{A} \delta$-fiber mechanonociceptors also had reduced firing, but only at high intensity forces $(>100 \mathrm{mN})$. Surprisingly, the firing rates of low-threshold $\mathrm{A} \beta$ and $\mathrm{D}$-hair mechanoreceptive fibers were also altered. TRPA1 protein and mRNA expression was assessed in DRG neurons and cutaneous innervation by using Trpa1 in situ hybridization, an antibody for TRPA1, and an antibody for placental alkaline phosphatase (PLAP) in mice in which PLAP was substituted for Trpa1. DRG neurons of all sizes expressed Trpa1 mRNA or PLAP immunoreactivity. TRPA1 or PLAP immunolabeling was detected not only on many thin-caliber axons and intraepidermal endings but also on many large-caliber axons as well as lanceolate and Meissner endings. Epidermal and hair follicle keratinocytes also express TRPA1 message and protein. We propose that TRPA1 modulates mechanotransduction via a cell-autonomous mechanism in nociceptor terminals and possibly through a modulatory role in keratinocytes, which may interact with sensory terminals to modify their mechanical firing properties.

\section{Introduction}

Transient receptor potential ankyrin 1 (TRPA1) is a member of the transient receptor potential (TRP) ion channel family, which is implicated in thermosensation (McKemy et al., 2002; Peier et al., 2002a; Moqrich et al., 2005), osmosensation (Liedtke and Friedman, 2003), and mechanosensation (Walker et al., 2000; Tracey et al., 2003). TRPA1 has six-transmembrane domains, cytoplasmic $\mathrm{N}$ and $\mathrm{C}$ termini, passes $\mathrm{Na}^{+}$and $\mathrm{Ca}^{2+}$, and probably forms tetrameric channels in native neurons. TRPA1 has an extended ankyrin repeat domain in the N-terminal. Ankyrin repeats have been hypothesized to modulate ligand binding (Lishko et al., 2007) or tether the channel to cytoskeletal components (Howard and Bechstedt, 2004; Sotomayor et al., 2005). Previous studies indicate that TRPA1 is expressed in small- to medium-diameter, peptide-containing neurons that express its

Received Nov. 7, 2008; revised Feb. 11, 2009; accepted Feb. 25, 2009.

This work was supported by funding from National Institutes of Health Grant NS40538 (C.L.S.). We thank Dan Tom at the Harvard NeuroDiscovery Center confocal core for technical advice and AstraZeneca for providing the TRPA1 antibody. We are grateful to James Kuchenbecker for designing the mechanical stimulator used for skinnerve experiments. We also thank Drs. Na Lu and Raymond G. Hoffman (Division of Biostatistics, Medical College of Wisconsin, Milwaukee, WI) for assistance with statistical comparisons and interpretation. K.Y.K. was an Associate and D.P.C. is an Investigator of the Howard Hughes Medical Institute.

*K.Y.K. and J.M.G. contributed equally to this work.

Correspondence should be addressed to Dr. Cheryl L. Stucky, Department of Cell Biology, Neurobiology and Anatomy, Medical College of Wisconsin, 8701 Watertown Plank Road, Milwaukee, WI 53226. E-mail: cstucky@mcw.edu.

DOI:10.1523/JNEUROSCI.5380-08.2009

Copyright $\odot 2009$ Society for Neuroscience $\quad$ 0270-6474/09/294808-12\$15.00/0 relative, TRPV1 (Story et al., 2003; Bautista et al., 2005; Kobayashi et al., 2005; Nagata et al., 2005), a multimodal channel activated by capsaicin, heat, and inflammatory chemicals (Caterina et al., 2000). Like TRPV1, TRPA1 is a proposed molecular integrator of chemical and physical sensory stimuli. TRPA1 is directly activated by pungent or irritating compounds in mustard oil (allyl isothiocyanate), cinnamon oil (cinnamaldehyde), garlic (allicin), and exhaust fumes (acrolein) (Bandell et al., 2004; Jordt et al., 2004; Macpherson et al., 2005; Bautista et al., 2006). In contrast, evidence for TRPA1 activation by physical stimuli is ambiguous. TRPA1 has been proposed to directly transduce noxious cold: one group found that TRPA1-transfected heterologous cells are activated by $17^{\circ} \mathrm{C}$ (Story et al., 2003); however, other groups found no direct cold activation (Jordt et al., 2004; Nagata et al., 2005; Zurborg et al., 2007). Behavioral deficits to noxious cold have been found in Trpa1 ${ }^{-1-}$ mice (Kwan et al., 2006), but another group found no cold deficits (Bautista et al., 2006). TRPA1 has been implicated in behavioral cold hyperalgesia after injury (Obata et al., 2005; Katsura et al., 2006).

TRPA channels have also been proposed to be involved in mechanotransduction. Drosophila larvae deficient in painless, an invertebrate TRPA, have reduced mechanical nociception (Tracey et al., 2003). Caenorhabditis elegans Trpal mutants fail to show head withdrawal after nose touch (Kindt et al., 2007). Mice deficient in TRPA1 have decreased behavioral responses to noxious force (Kwan et al., 2006), although defects were not observed in another Trpal mutant (Bautista et al., 2006). Behavioral tests 
are complicated by multiple factors, including influence of central descending pathways, different test methods, and other mechanotransduction components in sensory neurons (Price et al., 2000, 2001; Jones et al., 2005; Mogil et al., 2005; Wetzel et al., 2007).

To understand the role of TRPA1 in cold and mechanical sensation, it is important to consider the cellular milieu (native or heterologous cells), the tissue setting (injured, inflamed, or naive tissue), the physiological relevance of the region studied (somata or nerve terminal), and the components integrated into the response (animal behavior or single-cell responses). Therefore, we used the skin-nerve preparation from noninjured mice to determine the contribution of TRPA1 to acute cold and mechanical force at the sensory terminal in situ.

\section{Materials and Methods}

Skin-nerve preparation and fiber analysis. The mouse saphenous skinnerve ex vivo preparation (Koltzenburg et al., 1997; Stucky et al., 1999) was used for electrophysiological functional assessments of cutaneous terminals of primary afferent fibers in situ. Recordings were conducted on adult male mouse littermates (age $8-22$ weeks) that were wild type $\left(\operatorname{Trpa1} 1^{+/+}\right)$or that had heterozygous $\left(\operatorname{Trpa1} 1^{+/-}\right)$or homozygous $\left(\right.$ Trpa $\left.^{-1-}\right)$ deletions in which the entire TRPAl pore domain was replaced with placental alkaline phosphatase (PLAP) reporter gene (i.e., Trpa1 ${ }^{\text {+/PLAP }}$ or Trpa1 $1^{\text {PLAP/PLAP }}$ ) (Kwan et al., 2006). All experiments and data analyses were performed with the operator blind to genotype. Mice were anesthetized with isoflurane and killed by cervical dislocation. The saphenous nerve and skin from the medial dorsum of the hindpaw were rapidly dissected free and placed corium side up into a bath superfused with oxygen-saturated synthetic interstitial fluid containing the following (in mM): $123 \mathrm{NaCl}, 3.5 \mathrm{KCl}, 0.7 \mathrm{MgSO}_{4}, 1.7 \mathrm{NaH}_{2} \mathrm{PO}_{4}, 2.0$ $\mathrm{CaCl}_{2}, 9.5$ sodium gluconate, 5.5 glucose, 7.5 sucrose, and 10 HEPES, 290 $\mathrm{mOsm}$, at $\mathrm{pH} 7.45 \pm 0.05$ and temperature of $32.0 \pm 0.5^{\circ} \mathrm{C}$. The saphenous nerve was desheathed and teased into fine filaments for extracellular recordings, as described previously (Stucky et al., 1999). Single afferent units were identified using either an electrical search stimulus or a mechanical search stimulus as indicated. For electrically identified fibers, a Teflon-coated steel needle electrode ( $2 \mathrm{M} \Omega$ impedance; uninsulated tip diameter of $10 \mu \mathrm{m}$ ) was inserted systematically across the skin preparation while square-wave pulses $(500 \mu \mathrm{s} ; 6 \mathrm{~mA})$ were applied. After action potential identification (signal/noise ratio, $>3$ ), the surrounding tissue was probed to identify the lowest electrical threshold. This point corresponded reliably with the most mechanically sensitive part of the receptive field in mechanically sensitive fibers as determined by calibrated von Frey filaments. A unit was considered mechanically insensitive if it did not respond to any force $\leq 147 \mathrm{mN}$. For mechanically identified fibers, a blunt glass rod was used to locate units across the skin (Stucky et al., 1999). Once a unit with a signal/noise ratio of $>3$ was identified, the mechanical threshold was determined using calibrated von Frey filaments (range, $0.044-147.0 \mathrm{mN}$ ).

For fibers located with either an electrical or mechanical search stimulus, the conduction velocity was calculated as described previously (Koltzenburg et al., 1997; Stucky et al., 1999). In agreement with previous studies from mouse, units conducting slower than $1.2 \mathrm{~m} / \mathrm{s}$ were classified as unmyelinated C-fibers; those conducting between 1.2 and $10 \mathrm{~m} / \mathrm{s}$ were classified as thinly myelinated $\mathrm{A} \delta$-fibers; and units conducting faster than $10 \mathrm{~m} / \mathrm{s}$ were classified as myelinated $A \beta$-fibers. Mechanically sensitive $\mathrm{A} \beta$-fibers were further categorized as slowly adapting (SA) if they responded throughout a sustained force of $10 \mathrm{~s}$ duration, or rapidly adapting (RA) if they responded only at the onset or offset of force. Mechanically sensitive $\mathrm{A} \delta$-fibers were classified as A-mechanoreceptor (AM)fibers if they exhibited slowly adapting responses to sustained force, or as down-hair (D-hair) receptors if they were rapidly adapting. Mechanically sensitive units were further tested with quantitative force using a custom-made feedback-controlled computer-driven stimulator that controlled a cylindrical probe (tip diameter, $0.60 \mathrm{~mm}$ ) placed perpendicular to the most mechanically sensitive spot of the receptive field, as previously described (Stucky et al., 1999). Each fiber was tested with square-wave mechanical force in ascending order of $5,10,20,40,100$, 150 , and $200 \mathrm{mN}$ (10 s each; 1 min interstimulus interval).

For cold tests, all fibers were identified using electrical search stimuli, and C- and AM-fibers were characterized for cold responsiveness. Cold stimuli were delivered as previously described (Bautista et al., 2007): first, physiological zero $\left(32^{\circ} \mathrm{C}\right)$ was applied to the isolated receptive field for 20 s. Next, a cold ramp was applied in which buffer at the receptive field changed from 32 to $2^{\circ} \mathrm{C}$ over a $20 \mathrm{~s}$ duration and actual temperature at the receptive field was measured using a rapid time-constant thermoprobe (Physitemp Instruments). The number of action potentials evoked during the $32^{\circ} \mathrm{C}$ buffer stimulus ( $20 \mathrm{~s}$ ) was subtracted from the total number evoked during the cold ramp. For each fiber, cold threshold was identified as the temperature at which the firing rate exceeded five times the SD of the baseline firing rate sampled during the $32^{\circ} \mathrm{C}$ stimulus.

Wave forms of action potentials evoked by mechanical, electrical, or cold stimuli were saved on an oscilloscope for comparison of shape and profile. All data were collected using a Powerlab 4.0 system and Chart software (ADInstruments) and saved for off-line analysis. Action potentials were discriminated and counted off-line using a spike histogram software extension. For fibers that exhibited ongoing firing, a baseline firing rate was measured for $1 \mathrm{~min}$ before stimulus application, and an average for each $10 \mathrm{~s}$ was calculated. Stimulus-evoked action potential counts were determined by subtracting the baseline firing rate for $10 \mathrm{~s}$ from the action potentials that occurred during each $10 \mathrm{~s}$ of mechanical force.

Values are given as either mean \pm SEM, or median and 25th and 75th percentiles. Statistical comparisons between two groups included an unpaired two-tailed $t$ test for conduction velocity, cold thresholds, and number of cold-activated spikes. Fisher's exact test was used to compare percentage of neurons responding or percentage of neurons with a phenotype between two groups (GraphPad InStat). von Frey thresholds were compared by a Mann-Whitney $U$ test (Statistica; StatSoft). For comparison of action potentials generated over the entire force continuum between the genotypes, a mixed-effects ANOVA model was used in which genotype and force were treated as fixed effects (SAS, version 9.1.3, software). The mixed-effects ANOVA model allowed the intercept of the individual fiber to be treated as a random effect so that the entire effect of genotype on the force response curve could be accurately modeled and tested. The $p$ values for force, genotype, and the interaction of the two variables test the effect of each of these on the response patterns observed for each fiber type.

Immunostaining and in situ hybridization of tissue. Immunochemical and mRNA assessments of dorsal root ganglion neurons and immunochemical assessments of cutaneous innervation were conducted on adult male littermates (6-8 weeks of age) that were Trpa1 ${ }^{+/+}, \operatorname{Trpa1} 1^{+/ \mathrm{PLAP}}$, or Trpa1 ${ }^{\text {PLAP/PLAP }}$ (Kwan et al., 2006). For hairy skin, Nair (Church \& Dwight) was applied for $5 \mathrm{~min}$ before killing and wiped off to remove hair on the medial dorsal portion of the hindpaw. Some mice were killed and perfused with ice-cold $0.1 \mathrm{M}$ PBS at $\mathrm{pH} 7.4$ containing $4 \%$ paraformaldehyde and postfixed in the same fixative for $4 \mathrm{~h}$. Medial dorsal hairy skin and ventral glabrous skin were dissected from the hindpaws and rinsed and stored in cold PBS. Other mice were killed, and the skin and dorsal root ganglia were removed as quickly as possible in cold HEPES-buffered saline solution without $\mathrm{Ca}^{2+}$ or $\mathrm{Mg}^{2+}$. Skin from some of these mice was fixed by immersion in PBS containing $4 \%$ paraformaldehyde at $4^{\circ} \mathrm{C}$ for $4 \mathrm{~h}$. Other unfixed skin was flash frozen in isopentane at a temperature equilibrated to liquid nitrogen. Fixed skin was cryoprotected with $30 \%$ sucrose and frozen in Neg50. The frozen fixed and unfixed skin was cut on a cryostat at 14 or $30 \mu \mathrm{m}$ thickness, and the sections were thawed onto slides. Sections cut from unfixed flash-frozen skin were fixed on slides in $4 \%$ paraformaldehyde or acetone for $10 \mathrm{~min}$. Sections were permeabilized with PBS containing $0.1 \%$ Triton X-100 treated with Image-iT FX enhancer (Invitrogen) before incubating in unconjugated goat antimouse monovalent $\mathrm{F}_{\mathrm{ab}}$ (Jackson ImmunoResearch Laboratories) containing $0.13 \mu \mathrm{g} / \mathrm{ml}$ antibody (1:10,000 dilution) at room temperature for $30 \mathrm{~min}$. Slides were then blocked in $1 \times$ PBS containing $10 \%$ normal goat serum and $0.1 \%$ Triton $\mathrm{X}-100$ for $1 \mathrm{~h}$ at room temperature before incubation overnight at $4^{\circ} \mathrm{C}$ with the same solution containing mouse anti- 
PLAP (Sigma-Aldrich) at 1:100 together with either rabbit anti-human PGP9.5 (Ultraclone) at 1:500, rabbit anti-bovine $200 \mathrm{kDa}$ neurofilament protein (NF) (Millipore Bioscience Research Reagents), or anti-human TRPA1 (AstraZeneca). After primary antibody incubation, slides were washed with $1 \times \mathrm{PBS} / 0.1 \%$ Triton $\mathrm{X}-100$ before incubation in secondary antibody solution containing 1:1000 of both goat anti-mouse IgG $\gamma 2 \mathrm{a}$ Alexa Fluor 568 and goat anti-rabbit IgG Alexa Fluor 488 (Invitrogen) for $2 \mathrm{~h}$ at room temperature, washed in $1 \times \mathrm{PBS} / 0.1 \%$ Triton X-100, and rinsed in $1 \times$ PBS before mounting in antifade reagent.

Dorsal root ganglia (DRGs) (lumbar 2-6) were also removed from perfusion-fixed and from unfixed wild-type and mutant mice. Unfixed DRGs were flash frozen and perfusion-fixed tissue was cryoprotected and frozen in Neg50 for cryostat sectioning as described above. Fixed DRG sections were processed for immunochemistry as described above.

For in situ hybridization, a cRNA probe was generated from $2600-$ 3338 bp of the Trpa1 coding sequence with digoxigenin (DIG)-labeled dUTP and hybridized to sections cut from unfixed, flash-frozen skin and DRG sections as described previously (Corey et al., 2004). These sections were then postfixed in $4 \%$ formaldehyde for $10 \mathrm{~min}$ before continuing with the immunostaining procedures stated above. The in situ probe was detected using a sheep anti-DIG antibody (Roche Applied Science) at 1:500 dilution followed by a donkey anti-sheep IgG Alexa Fluor 488 secondary antibody (Invitrogen) at 1:1000 dilution. PLAP immunostaining was done in parallel as described above.

Images were acquired using a Zeiss LSM 510 confocal microscope equipped with a $40 \times /$ numerical aperture 1.3 Neofluar objective and an Olympus Provis AX70 microscope equipped for conventional epifluorescence: (1) Cy3 filters (528-553 nm excitation; 590-650 $\mathrm{nm}$ emission) and (2) Cy2 filters (460-500 nm excitation; 510-560 nm emission). Immunofluorescent images of DRG cell bodies and fibers from tissue sections were evaluated with the experimenter blinded to the genotype of the animal from which the tissue was derived. Morphometric analyses of the double-labeling combinations in DRGs were performed with Neurolucida software (MBF Biosciences) according to procedures described in detail previously (Cannon et al., 2007). Briefly, the intensity of the digital images was enhanced to reveal even the weakest profiles because of likely autofluorescence, and the contours of all the cells were circumscribed to calculate the area and diameter of each cell. The contour outlines were transferred onto the unenhanced images of the separate red and green channels. In each channel, the labeling of the cell underlying each contour was rated from 1 to 5 based on the pixel values, with 5 being the highest values and 1 being the lowest. The independent results from each channel were combined to determine which cells had labeling for either or both antibodies. Only those cells regarded as 3-5 in each channel were regarded as "labeled" for the antibody corresponding to the particular channel.

\section{Results}

\section{TRPA1-deficient cutaneous afferent fibers have no loss in acute cold sensitivity}

From psychophysical experiments, noxious cold evokes multiple percepts that have distinct sensations and time courses (Davis and Pope, 2002). We tested the contribution of TRPA1 to the first, acute phase of cold sensation, measuring at the level of the sensory afferent terminal in skin from naive mice. Recently, we showed that mice lacking the menthol receptor TRPM8 have a striking decrease in both the number of cutaneous $\mathrm{C}$-fiber neurons responding and in the number of cold-evoked action potentials (Bautista et al., 2007). Using the same approach and methods, we asked whether cutaneous fibers from mice that lack TRPA1, which also contain the PLAP marker under the Trpal promoter (Kwan et al., 2006), exhibit deficits in cold sensitivity. Since most cold-sensitive afferents have C- or $\mathrm{A} \delta$-fiber axons in vivo, and since Trpa1 mRNA has been localized to small- and medium-diameter sensory neurons, many of which are C- and A $\delta$-fiber nociceptors (Jordt et al., 2004; Kobayashi et al., 2005; Nagata et al., 2005), we tested the cold sensitivity of C-fibers and high-threshold AM-fibers in skin-nerve preparations isolated from $\operatorname{Trpa1}^{-1-}$ and wild-type littermates. Fibers were located with an electrical search strategy and characterized by conduction velocity to identify neurons in a manner unbiased by modality, and then classified as C-fibers $(<1.2 \mathrm{~m} / \mathrm{s})$ or $\mathrm{A} \delta$ AM-fibers $(1.2-10 \mathrm{~m} / \mathrm{s})$. Cold stimuli were applied as a ramp of cold buffer ( 32 to $2^{\circ} \mathrm{C}$ over $20 \mathrm{~s}$ ) delivered to the receptive field. C-fibers from Trpa1 ${ }^{-I-}$ mice responded normally to the acute cold stimuli. In both mutant and wild-type mice, $30 \%$ of C-fibers responded to cold (Fig. 1a,b), and cold-sensitive C-fibers from Trpa $1^{-1-}$ mice responded with a firing rate comparable with wild-type controls (Fig. 1c). There was also no difference in the mean cold threshold for C-fibers from the two cohorts $\left(\operatorname{Trpa} 1^{+/+}: 11.8 \pm 2.0^{\circ} \mathrm{C}\right.$; range, $1.5-24.9^{\circ} \mathrm{C}$; $\operatorname{Trpa1}^{-1-}: 13.8 \pm 1.7^{\circ} \mathrm{C}$; range, $1.3-30.0^{\circ} \mathrm{C}$; mean \pm SEM; $p>0.5$; unpaired $t$ test). Likewise, AM-fibers from Trpa1 ${ }^{-1-}$ mice responded to cold as well as AM-fibers from wildtype littermates: there were no significant differences in the proportion responding, magnitude of response (Fig. $1 d-f$ ), or cold thresholds $\left(\right.$ Trpa1 ${ }^{+/+}: \quad 7.6 \pm 1.8^{\circ} \mathrm{C}$; range, $3.0-11.3^{\circ} \mathrm{C}$; Trpa1 ${ }^{-1-}: 16.7 \pm 4.6^{\circ} \mathrm{C}$; range, $2.3-29.6^{\circ} \mathrm{C} ; p>0.1$; unpaired $t$ test). Together, these data indicate that TRPA1 does not contribute to acute cold transduction at the level of the cutaneous primary afferent terminal in noninjured skin.

\section{Mechanically sensitive cutaneous fibers are present in normal numbers in TRPA1-mutant mice}

Behavioral studies implicate a role for TRPA1 in somatosensory mechanotransduction in that Trpa1 ${ }^{-1-}$ mice exhibit deficits in response to intense mechanical force (Kwan et al., 2006) and pharmacological inhibition of TRPA1 blocks inflammatory mechanical hyperalgesia (Petrus et al., 2007). But clear evidence for involvement of TRPA1 in the responsiveness of primary afferent fibers to mechanical stimuli is lacking. Thus, we next asked whether the absence of TRPA 1 alters the mechanical sensitivity of cutaneous primary afferent terminals. First, to determine whether TRPA1 is necessary for the presence of mechanically sensitive afferent terminals in skin, we used an electrical search technique to identify all subtypes of cutaneous afferents, regardless of sensory modality (Kress et al., 1992; Wetzel et al., 2007). Fibers were classified by conduction velocity into $A \beta-(>10 \mathrm{~m} / \mathrm{s})$, A $\delta-(1.2-10 \mathrm{~m} / \mathrm{s})$, and C-fibers $(<1.2 \mathrm{~m} / \mathrm{s})$. The mechanical threshold of each fiber was determined using calibrated von Frey filaments $(0.044-147 \mathrm{mN})$ by systematically probing the entire preparation. If a fiber did not respond to any mechanical stimulus, it was classified as mechanically insensitive. In Trpa1 ${ }^{+/+}$ mice, $86 \%$ of $\mathrm{A} \beta$-, $96 \%$ of $\mathrm{A} \delta$-, and $92 \%$ of $\mathrm{C}$-fibers responded to mechanical force. These proportions were the same in Trpa1 ${ }^{-1-}$ mice (Fig. $2 a$ ). Thus, TRPA1 is not required for the development or survival of any subtype of mechanically sensitive afferent terminal in skin.

Mechanically sensitive myelinated cutaneous fibers can be classified into different subtypes based on their pattern of action potential firing during a force stimulus. $\mathrm{A} \beta$-fibers are almost evenly divided between SA and RA subtypes, whereas A $\delta$-fibers are divided between high-threshold mechanoreceptor (AM)fibers and very-low-threshold D-hair mechanoreceptors (Koltzenburg et al., 1997). In a separate set of experiments, we used a mechanical search stimulus to randomly locate mechanically sensitive cutaneous fibers and to categorize fibers into these subclasses. There were no significant differences in the proportions of subtypes of $\mathrm{A} \beta$ - or $\mathrm{A} \delta$-fibers in Trpa1 ${ }^{-1-}$ mice compared with wild-type littermates (Fig. 2b). Thus, TRPA1 is not required for 
a

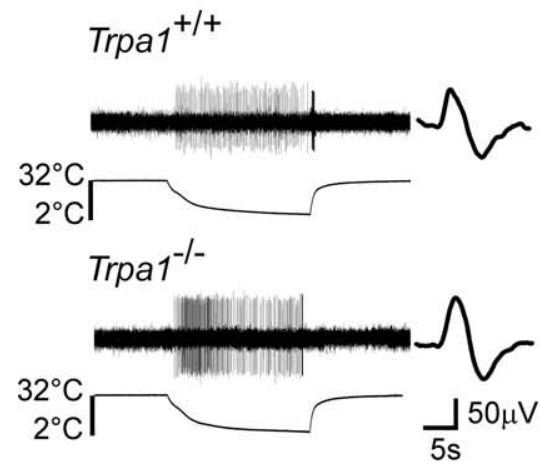

b

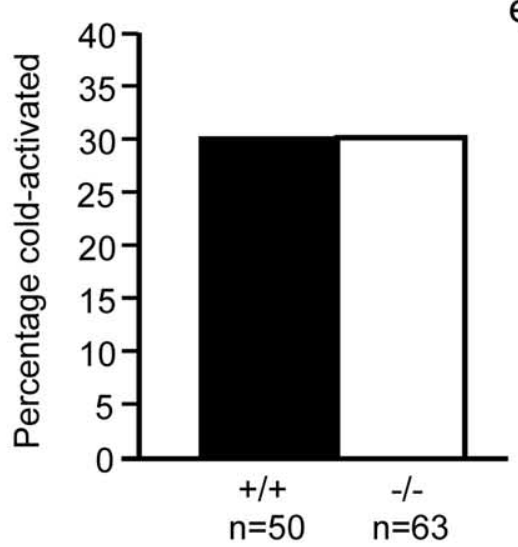

C

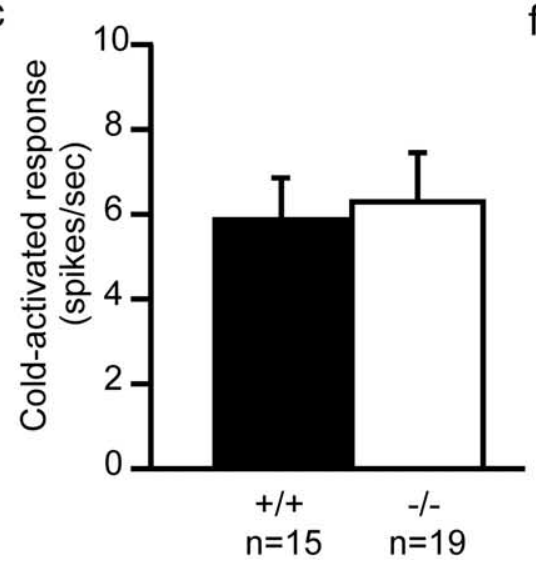

d
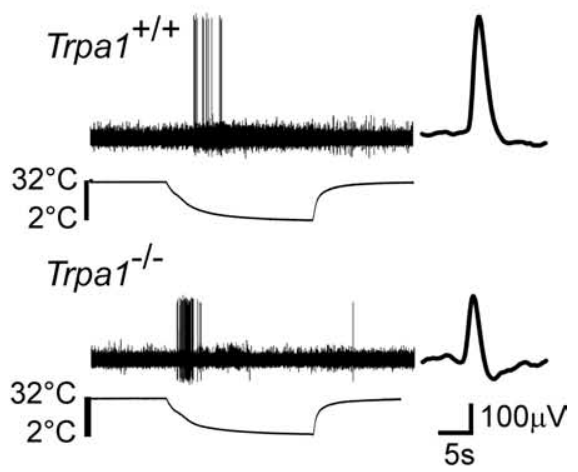

e

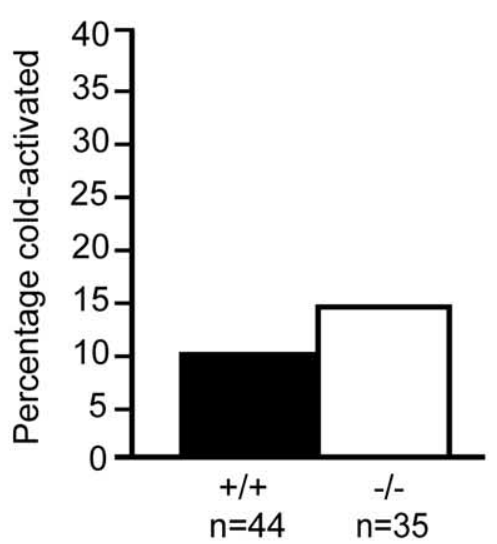

f

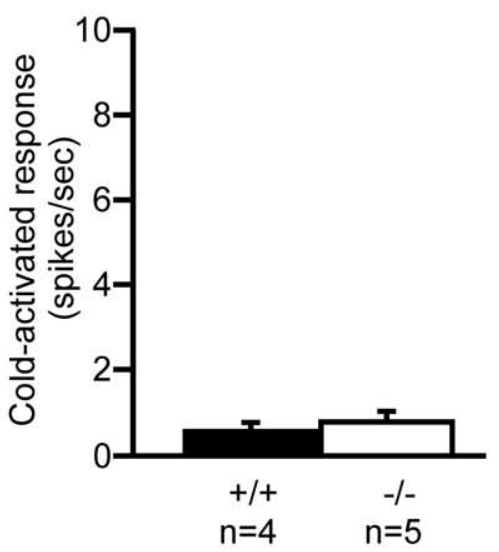

Figure 1. Cold activation in Trpa 1 mutant fibers. $\boldsymbol{a}$, Typical response of wild-type (top) and TRPA1-deficient (bottom) cutaneous C-fiber to a cold ramp $\left(32\right.$ to $2^{\circ} \mathrm{C}$, over $\left.20 \mathrm{~s}\right)$. Action potential waveform is shown at the right of the trace. $\boldsymbol{b}$, Percentage of C-fibers responding to cold ramp in wild-type versus Trpa ${ }^{-1-}$ mice. $c$, Average cold-evoked action potential firing rate in C-fibers from wild-type and Trpa ${ }^{-/-}$mice. $\boldsymbol{d}$, Typical response of AM-fiber from wild-type (top) and Trpa $1^{-1-}$ mouse to cold ramp $\left(32\right.$ to $2^{\circ} \mathrm{C}$, over 20 s). e, Percentage of AM-fibers responding to a cold ramp in wild-type and Trpa ${ }^{-1-}$ mice. $\boldsymbol{f}$, Average cold-evoked action potential firing rate in AM-fibers from wild-type and Trpa ${ }^{-1-}$ mice. Error bars indicate SEM.

establishing the receptor phenotype of any subtype of cutaneous mechanoreceptor.

Mechanically activated nociceptors from TRPA1 mutants exhibit markedly reduced action potential firing

We then determined whether absence of TRPA1 alters the response properties of mechanically sensitive fibers. We used a computer-driven, feedback-controlled mechanical stimulator to apply sustained force of increasing intensity to the most sensitive part of the receptive field of each fiber. We focused first on C-fibers and
A $\delta$-AM-fibers since many of these slowly adapting nociceptors normally express TRPA1.

C-fibers from TRPA1-null mice responded to sustained pressure with approximately one-half as many action potentials at all force intensities compared with wild-type controls $(p<0.0001)$ (Fig. $3 a, b)$. Furthermore, as force increased, the difference between Trpa1 $1^{-1-}$ and wildtype C-fibers increased proportionally. As a consequence, the median von Frey threshold of C-fibers was significantly higher in Trpa1 ${ }^{-1-}$ mice compared with wild-type controls (6.82 vs $4.0 \mathrm{mN} ; p=$ 0.004 ). The conduction velocity and electrical thresholds were not different between the two genotypes (conduction velocity: Trpa1 ${ }^{+/+}, 0.59 \pm 0.03 \mathrm{~m} / \mathrm{s}$; Trpa1 ${ }^{-1-}, 0.58 \pm 0.03 \mathrm{~m} / \mathrm{s}$; electrical threshold: Trpa1 ${ }^{+/+}, 2.90 \pm 0.14 \mathrm{~mA}$; Trpa $\left.{ }^{-1-}, 3.38 \pm 0.21 \mathrm{~mA}\right)$. Interestingly, C-fibers from heterozygous Trpa1 ${ }^{+/-}$ mice displayed an average mechanical stimulus response function that fell between those of $\operatorname{Trpa1}^{-/-}$and Trpa1 ${ }^{+/+}$ C-fibers (Fig. 3b), similar to the difference in behavioral response in heterozygotes (Kwan et al., 2006). It was significantly lower than wild-type fibers $(p=0.0078)$ and higher (but not significantly) than Trpa1 ${ }^{-1-}$ C-fibers. This suggests that deletion of a single allele of the Trpal gene results in a haploinsufficiency phenotype that contributes to the mechanical responsiveness of C-fibers.

The absence of TRPA1 also affected AM nociceptors: Trpa1 ${ }^{-/-}$AM-fibers showed reduced action potential firing, albeit only at high-intensity forces $>100$ $\mathrm{mN}(p=0.0062)$ (Fig. 3c,d). At lower forces, the responses of AM-fibers from Trpa1 ${ }^{-1-}$ mice were identical with those from wild-type littermates. Consistent with this observation, the median mechanical von Frey threshold was not different between the two cohorts $(4.0 \mathrm{mN}$ for both genotypes).

Slowly adapting, low-threshold A $\boldsymbol{\beta}$ fiber mechanoreceptors have reduced action potential firing

Surprisingly, SA A $\beta$-fibers that mediate light touch exhibited significantly reduced action potential firing across the entire force range in Trpa1 mutants (Fig. 4a) despite previous reports that TRPA1 is absent in large DRG neurons that would be the source of such fibers. The majority of SA A $\beta$-fibers have low mechanical thresholds and presumably innervate Merkel cells, although up to $20 \%$ of rodent $\mathrm{A} \beta$-fibers may be nociceptors (Djouhri and Lawson, 2004). The majority $(86 \%)$ of SA A $\beta$-fibers from wild-type mice had von Frey thresholds of $1 \mathrm{mN}$ or less (median, $0.66 \mathrm{mN}$ ); however, a small proportion (14\%) had von Frey thresholds $\geq 4$ 
a

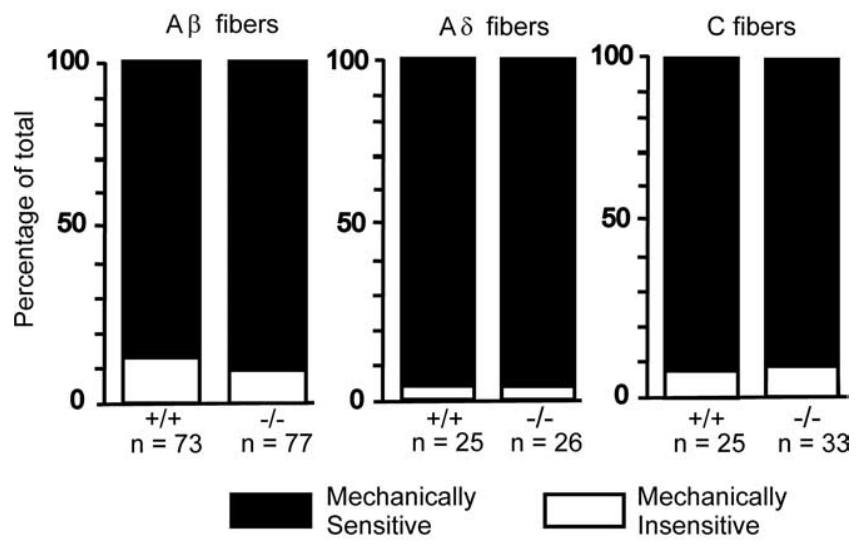

b
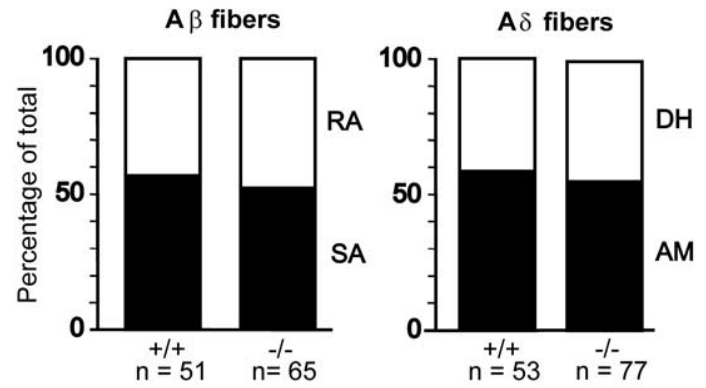

Figure 2. Mechanically sensitive afferents are present in normal proportions. $\boldsymbol{a}$, Percentage of all $\mathrm{A} \beta-, \mathrm{A} \delta$-, and $\mathrm{C}$-fibers encountered in Trpa ${ }^{-/-}$and wild-type preparations that were mechanically sensitive or mechanically insensitive. Fibers were identified using an electrical search protocol. Mechanically insensitive neurons did not respond to von Frey filaments up to $147 \mathrm{mN}$ or a glass rod stimulus. $\boldsymbol{b}$, Percentage of $A \beta$-fibers that were classified as $S A$ or RA based on responses to sustained force (left). Percentage of $A \delta$-fibers that were classified as D-hair receptors or $\mathrm{AM}$-fibers (right).

$\mathrm{mN}$. Thus, we further divided SA A $\beta$-fibers from both genotypes into "low-threshold" $(<4 \mathrm{mN})$ and "high-threshold" $(\geq 4 \mathrm{mN})$. Like AM-fibers, high-threshold SA A $\beta$-fibers from Trpa1 $1^{-1-}$ mutant mice showed deficits only at high-intensity forces $(\geq 100 \mathrm{mN}$ ) (Fig. $4 b$ ). Like C-fibers, low-threshold SA A $\beta$-fibers from Trpa1 ${ }^{-1-}$ mice were less responsive at all force intensities (Fig. 4c).

We then examined the adaptation rates to sustained force for each subtype of slowly adapting fiber. During a $10 \mathrm{~s}$ sustained, high-intensity $(150 \mathrm{mN})$ force, both C- and AM-fibers from Trpa1 ${ }^{-/-}$mice exhibited reduced firing both initially and throughout the duration of the stimulus (Fig. $5 a, b$ ). In contrast, SA A $\beta$-fibers displayed a normal initial firing rate, but adapted more rapidly, and so had reduced action potential firing throughout the remainder of the sustained stimulus. In the absence of TRPA1, high-threshold SA A $\beta$-fibers showed almost complete adaptation by $2 \mathrm{~s}$ (Fig. $5 c-e$ ). These data indicate that TRPA1 sets the initial firing rate of nociceptors to intense mechanical stimuli, and also participates in regulating the slowly adapting mechanical firing properties of myelinated cutaneous afferent fibers.

\section{Rapidly adapting cutaneous fibers from TRPA1 mutants} exhibit increased firing

We next analyzed rapidly adapting $\mathrm{A} \beta$-fibers and down-hair $\mathrm{A} \delta$ receptors, which innervate guard-hair and down-hair follicles, respectively. Unexpectedly, both $\mathrm{D}$-hair $\mathrm{A} \delta$-fibers and RA $\mathrm{A} \beta$ fibers from TRPA1-deficient mice had higher firing rates in response to force than in wild-type mice (Fig. 4d,e). Whereas $\mathrm{D}$-hair fibers were more responsive only at low forces, RA A $\beta$ fibers were more responsive across the entire range. However, conduction velocity, electrical threshold, and mechanical threshold were unaltered in mutant mice (data not shown). These data suggest that TRPA1 normally restrains the action potential firing of rapidly adapting cutaneous fibers. The TRPA1-dependent properties of each cutaneous fiber type are summarized in Table 1.

\section{PLAP immunostaining correlates with Trpa1 transcript in all} sizes of DRG neurons

Our physiological assays revealed deficits in mechanical responses in multiple subclasses of cutaneous afferent fibers including low-threshold touch receptors. However, TRPA1 expression has been documented only in the cell bodies of small- to medium-diameter (presumptive nociceptive) DRG neurons. Since TRPA1-deficient mice express the PLAP marker under the Trpa1 promoter (Kwan et al., 2006) (Fig. 6a), cells that express, or would normally have expressed TRPA1, can be labeled for PLAP in Trpa1 ${ }^{+/-}$, or in Trpa1 ${ }^{-1-}$ mice. We therefore investigated the distribution of PLAP staining in DRGs. We first developed tissue sections of lumbar (L2-L6) DRGs from $\operatorname{Trpa1}^{-1-}$ mice in a precipitable PLAP substrate and found a reaction product in many DRG neurons (data not shown).

We next determined the overlap between PLAP immunolabeling and TRPA1 mRNA expression in the same tissue sections, using an antibody to PLAP and a TRPA1 in situ hybridization probe that anneals to the message in wild-type but not mutant animals (Fig. 6a). In Trpa1 ${ }^{-/-}$L2-L6 DRG sections, many neurons expressed detectable fluorescence for PLAP labeling, but not Trpa1 mRNA, as expected. Low levels of fluorescence for Trpa1 mRNA were detected in a few cells presumably representing nonspecific background (Fig. $6 d$ ). For example, of all the DRG neurons from Trpa1 ${ }^{-1-}$ mice with detectable fluorescence, $96.8 \%$ had fluorescence only for PLAP labeling, $0.7 \%$ only for Trpa1 mRNA labeling, and $2.6 \%$ for both (Fig. $6 g$ ). In Trpa ${ }^{+/+}$DRGs, in contrast, virtually no fluorescence for PLAP labeling was present ( $2 \%$ of all fluorescent cells), whereas many neurons were positive for Trpal mRNA (Fig. 6b). In Trpa1 ${ }^{+/-}$heterozygotes, as expected, many DRG neurons that were PLAP-positive were also positive for Trpal mRNA (Fig. 6c). Thus, in heterozygous animals, the PLAP signal is highly correlated with Trpa1 mRNA, and in homozygous Trpa1 $1^{-1-}$ mutants, most if not all DRG somata that normally would have expressed TRPA1 apparently survived the absence of a functional Trpal gene.

Importantly, our PLAP immunostaining and Trpa1 mRNA labeling was distributed across a full range of small- to large-size DRG neurons (Fig. 6h,i), although previous studies indicate that TRPA1 is limited to small- to medium-size neurons. Furthermore, double labeling with antibodies against the $200 \mathrm{kDa} N F$ protein and PLAP revealed that PLAP was coexpressed in small, medium, and large NF-positive neurons (Fig. 6e,f). The NF staining was not exclusively correlated to PLAP since some large NFpositive neurons lacked PLAP and some small NF-negative neurons were PLAP-positive (Fig. 6e,f).

TRPA1 is expressed by keratinocytes in the epidermis and hair follicles

Interestingly, considerable PLAP staining was present in keratinocytes of the epidermis in Trpa1 ${ }^{-1-}$ mice in glabrous skin (Fig. $7 b$ ) as well as in keratinocytes of the epidermis and hair follicles in 
a

C fiber

$\operatorname{Trpa1}^{+/+}$

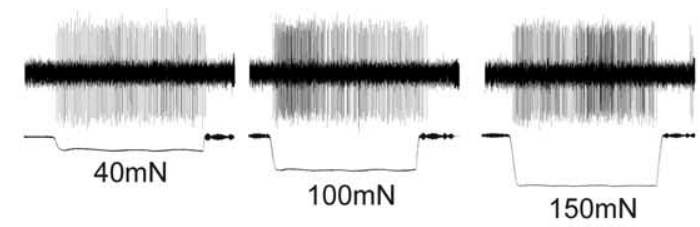

$\operatorname{Trpa1}^{-1-}$

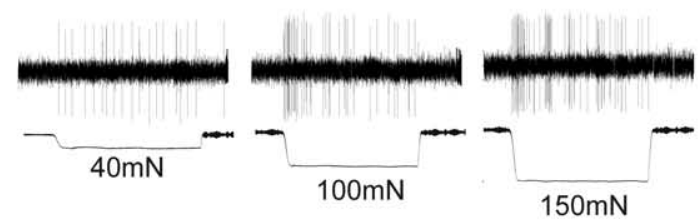

C AM fiber

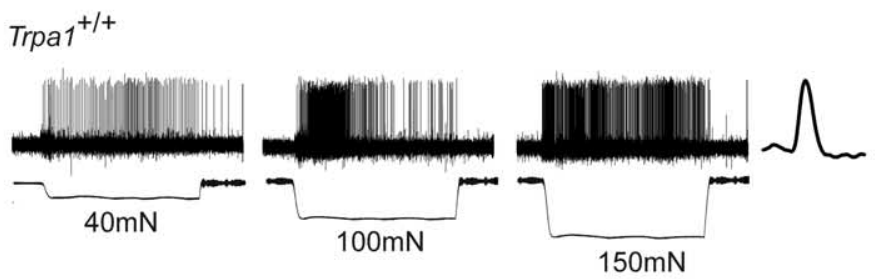

$\operatorname{Trpa1}^{-/-}$

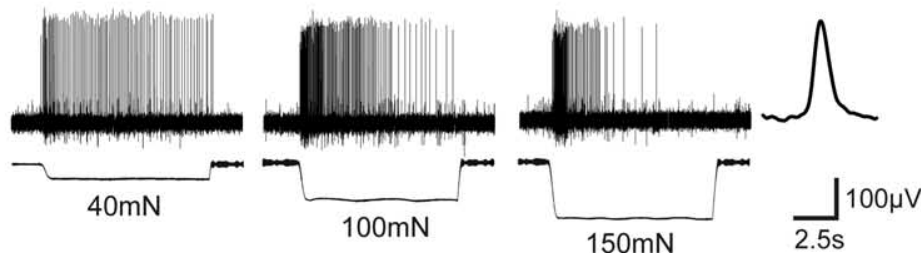

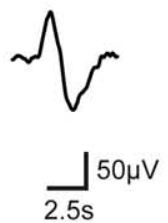

b
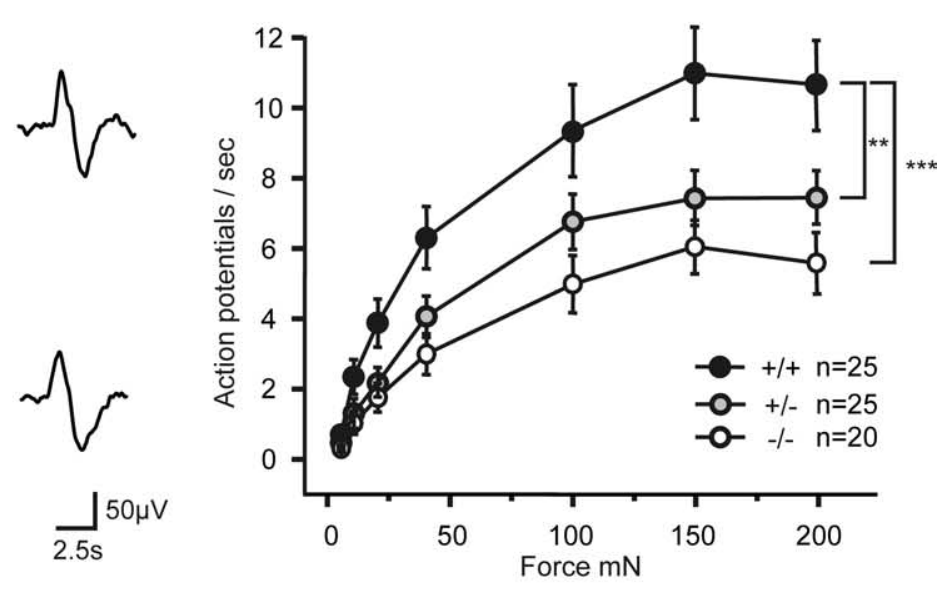

$\mathrm{d}$

AM Fibers

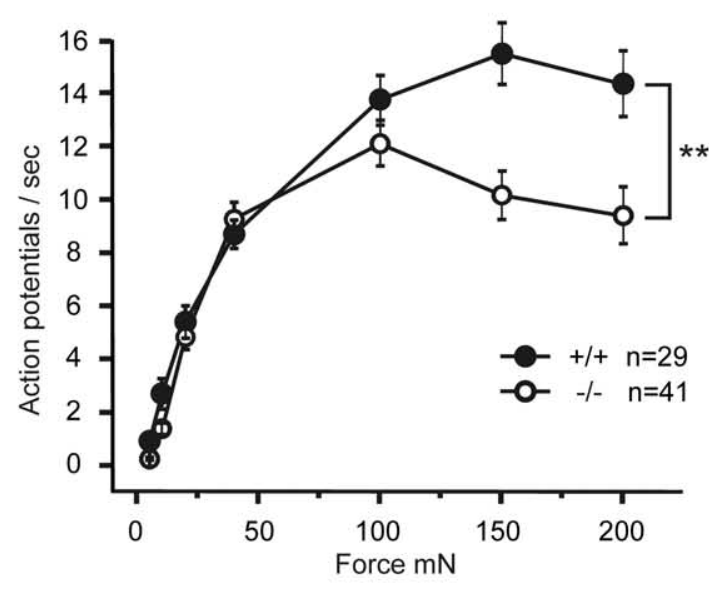

Figure 3. Nociceptors are less responsive to mechanical force. $\boldsymbol{a}$, Example of response of a C-fiber from a wild-type (top) and Trpa ${ }^{-1-}$ (bottom) mouse to sustained mechanical force (40, 100, $150 \mathrm{mN} ; 10 \mathrm{~s}$ each). $\boldsymbol{b}$, Average action potential firing rate per second to increasing sustained force (each stimulus $10 \mathrm{~s}$ ) in wild-type $(+/+)$, heterozygote $(+/-)$, and mutant $(-/-)(-$-fibers. C-fibers from Trpa ${ }^{-1-}$ mice responded with significantly fewer action potentials at all force intensities compared with $\operatorname{Trpa}^{+/+}{ }^{+ \text {-fibers }}{ }^{* * *} p<0.0001$ between genotypes; mixed-model ANOVA). Furthermore, as force increased, the difference increased proportionally between $\operatorname{Trpa}^{-1-}$ and wild-type $C$-fibers, and this was evident by a significant interaction between force and genotype ( $p=0.0074$ ). C-fibers from Trpa ${ }^{+/-}$heterozygotes also fired significantly fewer action potentials to force than wild-type $C$-fibers ${ }^{* * *} p=0.0078$ between genotypes; mixed-model ANOVA). c, Example of an AM-fiber from a Trpa $1^{+/+}$(top) and Trpa $1^{-/-}$(bottom) mouse to sustained mechanical force. $\boldsymbol{d}$, Average action potential firing rate to increasing force in AM-fibers. AM-fibers from $\operatorname{Trpa~}^{-1-}$ mice responded with significantly fewer action potentials than those from wild-type mice at intense forces $>100 \mathrm{mN}$ as evident by a significant interaction between force and genotype $(* * p=0062 ;$ mixed-model ANOVA). Error bars indicate SEM.

hairy skin from the dorsum of the hindpaw (Fig. 8d). Since PLAP is extracellular, the keratinocytes appear in a confocal section as prominent membrane fluorescence surrounding a dark cell body. PLAP labeling was lacking on keratinocytes in Trpa1 ${ }^{+/+}$mouse skin (Figs. $7 a, 8 c$ ). Consistent with the PLAP results, TRPA1 antiserum labeled keratinocytes in the epidermis and hair follicles of Trpa1 ${ }^{+/+}$skin (Figs. $7 d, 8 b$ ) but not in Trpa1 ${ }^{-1-}$ skin (Figs. $7 c$, $8 a)$. The sebaceous glands were also PLAP-positive in the mutants (Fig. $8 d$ ) and TRPA1-immunopositive in the wild-type mice (Fig. $8 b$ ). However, both sebaceous glands and hair shafts also exhibited substantial autofluorescence in $\operatorname{Trpa1} 1^{-/-}$mutants (Fig. 8a).

To confirm the presence of Trpal mRNA in keratinocytes, total RNA was prepared from glabrous skin and hairy skin taken from wild-type and mutant animal hindpaws, and was subjected to real-time PCR. A primer pair for cytokeratin 14, a keratinocyte-specific structural transcript, was used to normalize transcript levels. A primer pair that anneals to the wild-type but not mutant Trpal transcript was used for detection of Trpal mRNA. Confirming the PLAP expression, Trpal message was detected in both glabrous and hairy skin of wild-type animals, but not in mutant animals. Only the results from glabrous skin are shown (Fig. $7 f$ ).

TRPA1 is expressed in small- and large-caliber cutaneous fibers and endings

To investigate further where TRPA1 sensory fibers terminate and thus how they contribute to the behavioral response during a noxious mechanical stimulus, skin was immunostained with antibodies to PLAP, TRPA1, and PGP9.5. Nerves in the dermis of glabrous skin and hairy skin from Trpa1 ${ }^{-1-}$ mice contained axons that were PLAP-positive (Fig. 7b) and TRPA1immunonegative (Fig. $7 g$ ). Conversely, nerves in the dermis of Trpa1 ${ }^{+1+}$ mice were PLAP-negative (Fig. 7a) and TRPA1immunopositive (Fig. 7h). Consistent with the electrophysiological results and the wide range of sizes of the TRPA1-expressing 
DRG neurons, the labeled axons in the nerves included both small- and largecaliber fibers.

PGP9.5 immunolabeling revealed many fine-caliber intraepidermal endings in close proximity to keratinocytes in glabrous skin (Fig. 7a,b) and hairy skin (Fig. $8 c, d)$. In skin from Trpa1 ${ }^{+/+}$and Trpa1 ${ }^{-1-}$ mice, respectively, immunolabeling for TRPA1 and PLAP could be detected on some intraepidermal endings despite the extensive labeling on the keratinocytes (Figs. $7 d$, inset; $8 d$ ). Consistent with this evidence of TRPA1 on at least some intraepidermal endings, immunolabeling for TRPA1 and PLAP was also present, respectively, in $\operatorname{Trpa1} 1^{+/+}$and Trpa1 ${ }^{-1-}$ skin on thin-caliber fibers located at the border of the epidermis and in the upper dermis (Figs. $7 b, 8 d$ ). Fibers in this location are sources of intraepidermal endings. Immunolabeling was negative for TRPA1 on intraepidermal endings and upper dermal fibers in skin from Trpa $1^{-1-}$ mice (Figs. $7 c, 8 a$ ) and negative for PLAP in Trpa1 ${ }^{+/+}$mice.

Consistent our physiological results, TRPA1 and PLAP immunolabeling labeling was present on at least some types of $\mathrm{A} \beta$-fiber endings, especially those thought to be rapidly adapting low-threshold mechanoreceptors. A $\beta$-fiber lanceolate endings that are associated with hair follicles were PLAP-immunonegative and TRPA1-immunopositive in wild-type mice (Fig. 8f,g, respectively) and were PLAP-immunopositive in mutant mice (Fig. 8e). Meissner corpuscles in glabrous skin from wild-type mice were also labeled with anti-TRPA1 (Fig. 7e). We were unable to detect definitive expression of TRPA1 in Merkel cells or in their associated nerve fibers, which are thought to be slowly adapting low-threshold mechanoreceptors (data not shown). However, Merkel cells are embedded among the epidermal keratinocytes, which do express TRPA1. The proposed expression of TRPA1 related to specific cutaneous fiber types is summarized in Table 1.

Together, these data suggest that TRPA1 is expressed by keratinocytes as well as by nociceptive and low-threshold mechanosensitive fibers residing in and below the keratinocyte layer. TRPA1 in keratinocytes and sensory neurons may subserve different physiological functions in detecting noxious or innocuous mechanical stimuli.

\section{Discussion}

The physiological roles of TRPA1 in cold and mechanical sensation have received considerable attention in sensory neurobiolError bars indicate SEM.
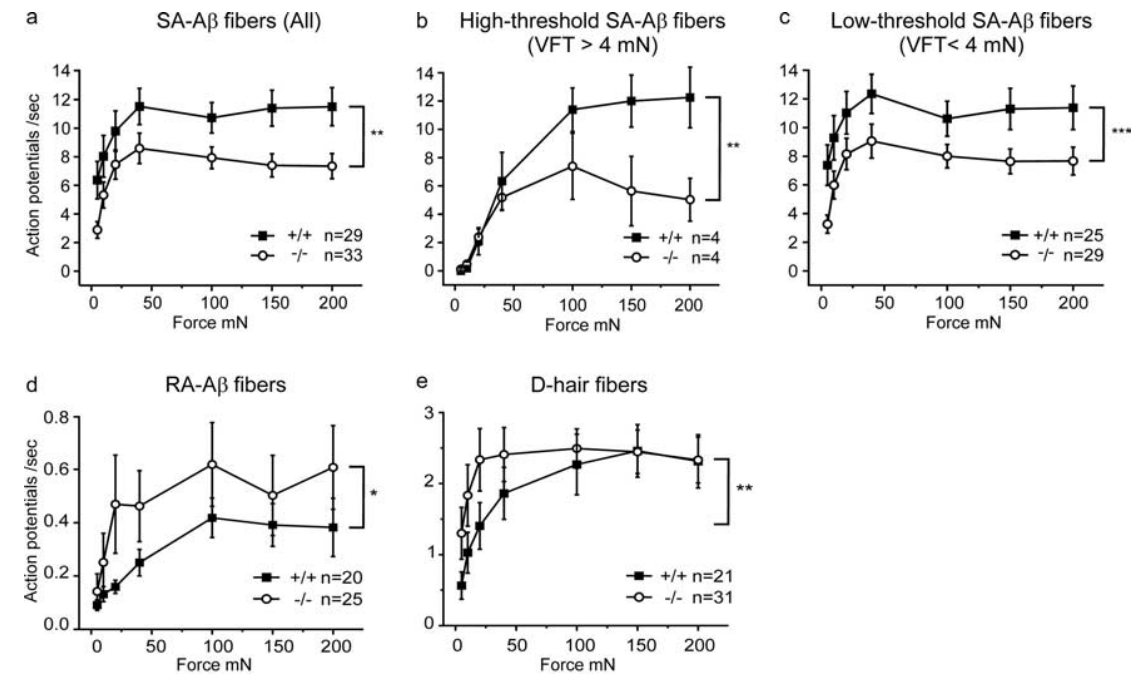

Figure 4. Mechanical firing is differentially altered in slowly versus rapidly adapting mechanoreceptors from Trpa 1 mutants. $\boldsymbol{a}$ Average action potentials per second in response to sustained force in all slowly adapting A $\beta$-fibers from Trpa ${ }^{-1-}$ and wildtype mice. SA A $\beta$-fibers from Trpa ${ }^{-1-}$ mice responded with significantly fewer action potentials at all force intensities compared with $\operatorname{Trpa}^{+/+} \mathrm{SAA} \beta$-fibers ( ${ }^{* *} p=0.0003$ between genotypes; mixed-model ANOVA). SA A $\beta$-fibers were divided into "high threshold" [von Frey threshold (VFT), $\geq 4 \mathrm{mN}$ ] (b) and "low threshold" (VFT, $<4 \mathrm{mN})(\boldsymbol{c})$. $\boldsymbol{b}$, High-threshold SA A $\beta$-fibers from $\operatorname{Trpa}^{-1-}$ mice responded with significantly fewer action potentials than those from wild-type mice, but the difference was present only at forces $>100 \mathrm{mN}$ as evident by a significant interaction between force and genotype $\left({ }^{* *} p=0.0074\right.$; mixed-model ANOVA). c, Low-threshold SA A $\beta$-fibers from Trpa ${ }^{-1-}$ mice responded with significantly fewer action potentials at all force intensities than these fibers from wild-type mice ${ }^{* * *} p<0.0001$ between genotypes; mixed-model ANOVA). $\boldsymbol{d}$, Average action potentials per second in RA A $\beta$-fibers. RA A $\beta$-fibers from $\operatorname{Trpa1}^{-1-}$ mice responded with significantly more action potentials than those in wild-type mice over all force intensities ( ${ }^{*} p=0.012$ between genotypes; mixed-model ANOVA). $\boldsymbol{e}$, Average action potentials per second in D-hair fibers. D-hair fibers from $\mathrm{Trpa1}^{-1-}$ mice responded to force with significantly more action potentials than those in wild-type mice at forces $<100 \mathrm{mN}$ (** $p=0.0011$ between genotypes). Error bars indicate SEM.
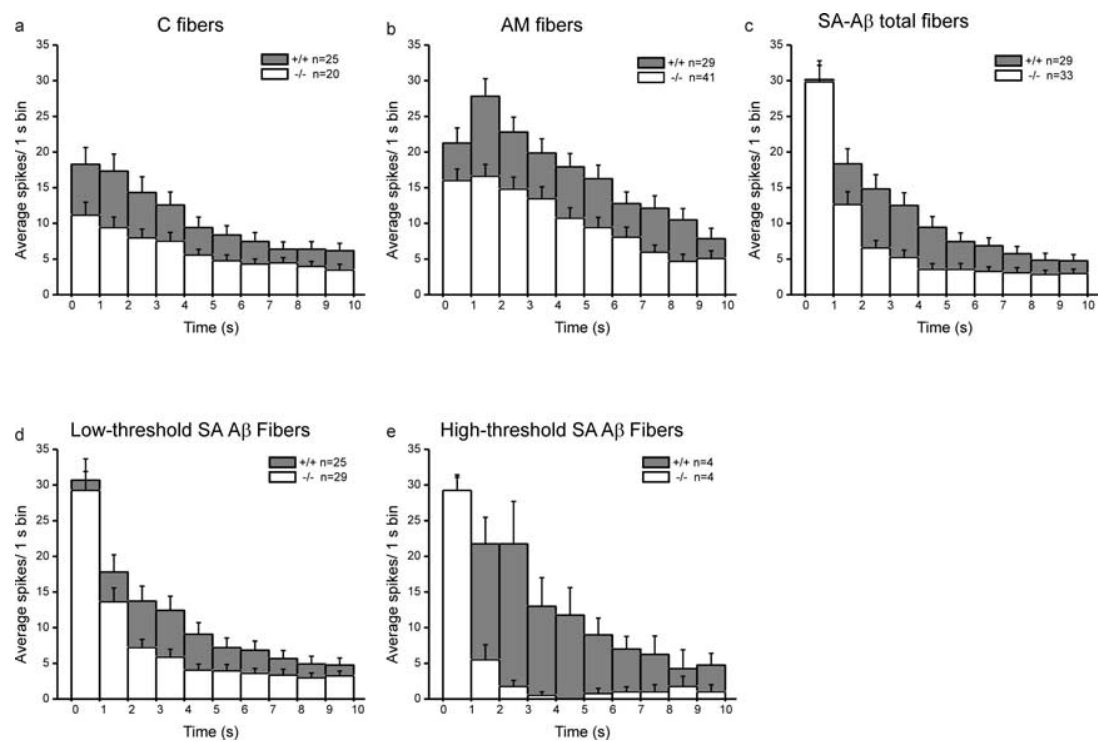

Figure 5. Adaptation properties of slowly adapting fibers are altered. Average action potentials per second during a $10 \mathrm{~s}$ sustained, intense $(150 \mathrm{mN})$ mechanical force in subclasses of slowly adapting fibers. Both C-fiber (a) and AM-fiber nociceptors (b) showed significantly reduced firing initially and during the entire duration of sustained force. SA A $\beta$-fibers (all) (c), including low-threshold $(\boldsymbol{d})$ and high-threshold $(\boldsymbol{e})$ subtypes, exhibited normal firing during the first second of force, but more rapid adaptation during the remaining stimulus duration. High-threshold SA A $\beta$-fibers showed almost complete adaptation by $2 s(\boldsymbol{e})$.

ogy. To determine the contribution of TRPA1 to acute cold and mechanical responses in sensory neurons themselves, we used the skin-nerve preparation, which allows the receptive terminals of identified cutaneous neurons to be quantitatively stimulated in an in situ environment and compared between wild-type and 
Table 1. Summary of fiber properties in the absence of TRPA1

\begin{tabular}{|c|c|c|c|c|c|c|c|}
\hline Fiber type & $\begin{array}{l}\text { Adaptation } \\
\text { property }\end{array}$ & $\begin{array}{l}\text { Conduction } \\
\text { velocity }\end{array}$ & $\begin{array}{l}\text { Mechanical } \\
\text { threshold }\end{array}$ & $\begin{array}{l}\text { Known regions of } \\
\text { innervation in hairy } \\
\text { skin }\end{array}$ & $\begin{array}{l}\text { Proposed TRPA1 expression re- } \\
\text { lated to fiber properties }\end{array}$ & $\begin{array}{l}\text { Effects of TRPA1 } \\
\text { absence on } \\
\text { mechanical } \\
\text { firing frequency }\end{array}$ & $\begin{array}{l}\text { Physiological role in } \\
\text { hairy skin }\end{array}$ \\
\hline$A \beta$ & SA & $>10 \mathrm{~m} / \mathrm{s}$ & Low (most) & Merkel cells & $\begin{array}{l}\text { Medium- to large-diameter neu- } \\
\text { rons and keratinocytes around } \\
\text { the Merkel cells }\end{array}$ & $\downarrow$ & $\begin{array}{l}\text { Fine touch two-point } \\
\text { discrimination }\end{array}$ \\
\hline $\mathrm{A} \delta-\mathrm{AM}$ & SA & $1.2-10 \mathrm{~m} / \mathrm{s}$ & High & $\begin{array}{l}\text { Free nerve endings } \\
\text { in epidermis and } \\
\text { dermis }\end{array}$ & $\begin{array}{l}\text { Small- to medium-diameter noci- } \\
\text { ceptors and keratinocytes }\end{array}$ & $\downarrow$ & Fast pain nociceptor \\
\hline C & SA & $<1.2 \mathrm{~m} / \mathrm{s}$ & $\begin{array}{l}\text { High (Trpa1 }{ }^{-1-} \text { have an } \\
\text { increased threshold) }\end{array}$ & $\begin{array}{l}\text { Free nerve endings } \\
\text { in epidermis and } \\
\text { dermis }\end{array}$ & $\begin{array}{l}\text { Small- to medium-diameter noci- } \\
\text { ceptors and keratinocytes }\end{array}$ & $\downarrow$ & Slow pain nociceptor \\
\hline$A \beta$ & RA & $>10 \mathrm{~m} / \mathrm{s}$ & Low & $\begin{array}{l}\text { Tylotrich and guard } \\
\text { hairs }\end{array}$ & $\begin{array}{l}\text { Medium- to large-diameter neu- } \\
\text { rons and keratinocytes in the } \\
\text { hair follicle }\end{array}$ & $\uparrow$ & Hair movement \\
\hline$A \delta$-D-hair & RA & $1.2-10 \mathrm{~m} / \mathrm{s}$ & Very low (<1 mN) & Down hairs & $\begin{array}{l}\text { Medium-diameter neurons and } \\
\text { keratinocytes in the hair follicle }\end{array}$ & $\uparrow$ & Hair movement \\
\hline
\end{tabular}

TRPA1-deficient mice. Here, we show that, in normal skin, TRPA1 is not required for acute cold transduction but does modulate the mechanically evoked firing rate of multiple classes of cutaneous sensory neurons.

Whether TRPA1 is directly gated by cold has been hotly debated. Some studies (Story et al., 2003), but not others (Jordt et al., 2004), found that TRPA1 expressed in heterologous cells is activated by cold. Single-channel recordings suggest that prolonged cold stimuli can activate TRPA1 by a membranedelimited mechanism (Sawada et al., 2007). TRPA1 has also been shown to function as a calcium-activated channel (Jordt et al., 2004), and mutations that abolish the calcium-binding capability of the EF-hand motif in TRPA1 eliminate its calcium-dependent activation (Doerner et al., 2007; Zurborg et al., 2007). Thus, colddependent elevation of intracellular $\mathrm{Ca}^{2+}$ has been proposed to explain activation of TRPA1 by cold temperatures in a heterologous expression system (Zurborg et al., 2007). Our data demonstrate that the terminals of native cutaneous $\mathrm{C}$ - and A $\delta$-fibers in situ do not require TRPA1 to respond to acute $(20 \mathrm{~s})$ cold stimuli. Using the same approach, we recently showed that TRPM8deficient mice have a striking loss in cold-sensitive C-fibers and cold-evoked action potentials (Bautista et al., 2007). The finding that cold responsiveness is normal in TRPA1-deficient $\mathrm{C}$ - and $\mathrm{A} \delta$-fibers indicates that TRPM8 is responsible for most or all of the acute cold sensitivity in both TRPA1-deficient and wild-type animals, although compensatory mechanisms or other unidentified mechanism(s) may exist. Our findings are consistent with the observation by Bautista et al. (2006) that Trpa1 ${ }^{-/-}$mice show no behavioral deficit in the latency to respond to acute cold stimuli. Whereas TRPA1 is not necessary for acute cold transduction, our results do not exclude the possibility that TRPA1 may be involved in the painful sensations associated with sustained cold exposure (Kwan et al., 2006). A recent study suggests that prolonged cold exposure activates heterologously expressed TRPA1 in a calciumindependent manner, and also found a reduction in a population of cold-sensitive trigeminal neurons and a deficit in avoidance of prolonged noxious cold in Trpa1 ${ }^{-1-}$ animals (Karashima et al.,
2009). TRPA1 may also contribute to cold hyperalgesia or allodynia after tissue injury (Obata et al., 2005).

The role of TRPA1 in sensation of painful mechanical stimuli has also been controversial (Bautista et al., 2006; Kwan et al., 2006). We found that TRPA1 is required for normal mechanical responsiveness in multiple subtypes of cutaneous sensory neurons. In the absence of TRPA1, slowly adapting C-fiber nociceptors exhibited only one-half the normal rate of mechanically evoked action potentials at all force intensities, whereas A $\delta$ mechanonociceptors showed reduced firing only to intense force $(>100 \mathrm{mN})$. The finding that both $\mathrm{C}$ - and AM-fiber nociceptors from TRPA1 mutants had reduced firing at the onset of force as well as throughout the duration of intense force indicates that TRPA1 participates in setting the action potential firing rate of nociceptors to intense force. The decreased mechanically evoked firing rate in nociceptors is consistent with the behavioral deficit in responses to intense mechanical force observed in $\operatorname{Trpa1}{ }^{-1-}$ mice (Kwan et al., 2006).

Unexpectedly, slowly adapting A $\beta$-fibers from TRPA1 mutants, originating from a neuronal subtype not known to express TRPA1, also exhibited reduced firing across all force intensities. Whereas their initial firing rate was normal, they exhibited faster adaptation to a sustained stimulus compared with wild-type controls. Thus, for SA A $\beta$-fibers, TRPA1 does not affect the initial rate of mechanically evoked firing but does modulate their characteristic slow adaptation to sustained force. In contrast to the reduced firing in all subclasses of slowly adapting fibers, rapidly adapting hair follicle afferents, including D-hair and RA A $\beta$-fibers, exhibited increased mechanically evoked firing in absence of TRPA1. Thus, TRPA1 differentially modulates the mechanical firing rate in all classes by conversely facilitating slowly adapting fibers and restraining rapidly adapting fibers.

It is not clear how TRPA1 differentially modulates the firing rate, but it may depend on the ion channel portfolio expressed in the two fiber classes. For instance, activation of TRPA1 in slowly adapting fibers might depolarize the terminals to assist in gener- 
a
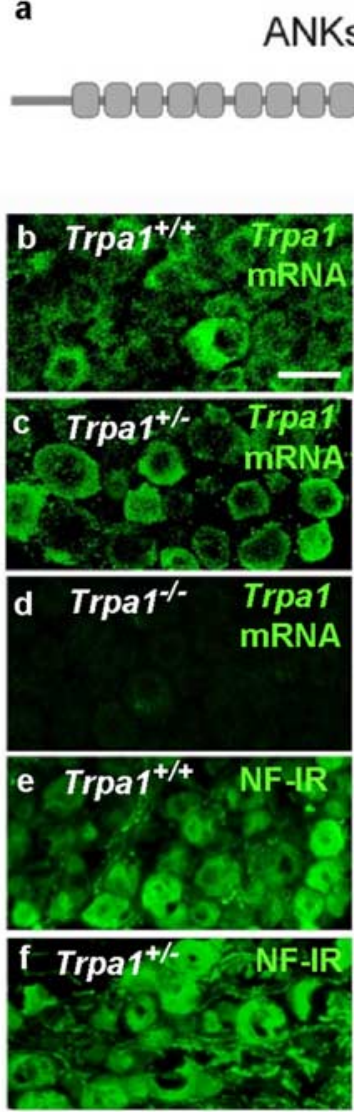

g

\begin{tabular}{lccc} 
& Trpa1 in situ & $\begin{array}{c}\text { Trpa1 in situ } \\
\text { and PLAP }\end{array}$ & PLAP \\
\cline { 2 - 4 } Trpa1 $^{+/+}$ & $98.0 \%$ & $0.4 \%$ & $1.6 \%$ \\
Trpa1 $^{+/-}$ & $2.8 \%$ & $95.9 \%$ & $1.3 \%$ \\
Trpa1 $^{-/-}$ & $0.7 \%$ & $2.6 \%$ & $96.8 \%$
\end{tabular}

h

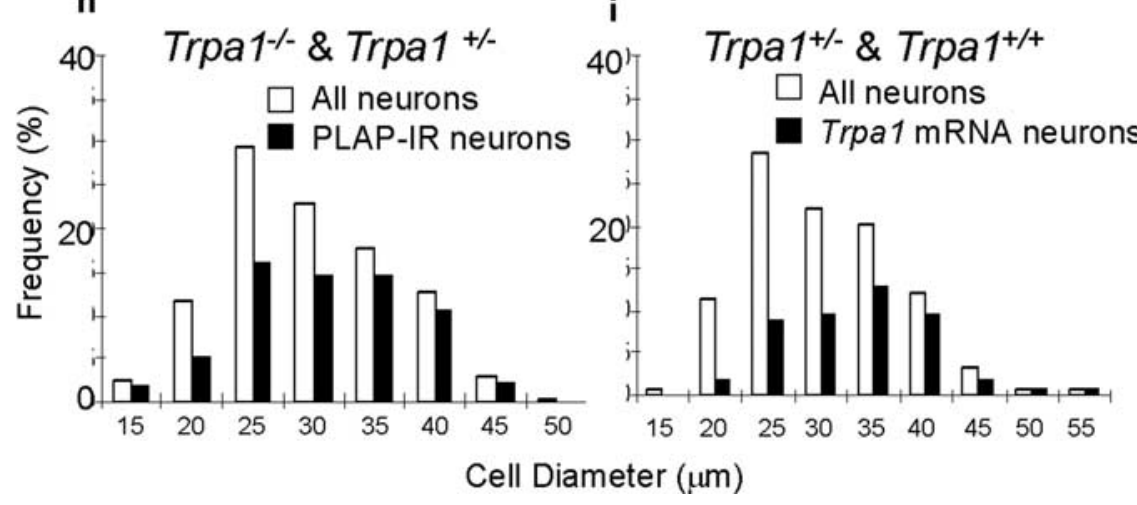

Figure 6. Correlation of Trpa1 transcript with PLAP reporter. In situ hybridization using a Trpa1 mRNA probe and PLAP immunostaining were sequentially performed on L2-L6DRG sections. $\boldsymbol{a}$, The in situ hybridization probe for Trpa $1 \mathrm{mRNA}$, which encodes the last two transmembrane domains and a portion of the C terminus, is represented by a green line. Only fluorescent DRG cell bodies were counted and analyzed. $\boldsymbol{b}$, In confocal images (three panels), Trpa1 mRNA was present but no PLAP immunoreactivity PLAP-IR) was observed in small, medium, and large DRG cell bodies (small, medium, and large green arrows, respectively) from Trpa $^{+1+}$ animals. Total DRG neurons analyzed, $n=488$. c, In confocal images (three panels) of Trpa ${ }^{+1-}$ heterozygote animals containing both Trpa 1 and the PLAP reporter, the vast majority of fluorescent neurons displayed both Trpa1 message and PLAP-IR. Total DRG neurons analyzed, $n=539$. Small, medium, and large neurons are double labeled (small, medium, and large yellow arrows). $\boldsymbol{d}$, In confocal images (three panels), small, medium, and large DRG neurons (small, medium, and large red arrows, respectively) from Trpa1 ${ }^{-1-}$ animals showed prominent PLAP-IR but no detectable Trpa1 in situ signal. Total DRG neurons analyzed, $n=465$. $\boldsymbol{e}$, In epifluorescence images (three panels), neurofilament immunoreactivity (NF-IR) is present without PLAP-IR on small, medium, and large DRG neurons in Trpa ${ }^{+/+}$animals (small, medium, and large green arrows, respectively). ating action potentials, whereas, in rapidly adapting fibers, calcium influx through TRPA1 might open calcium-activated potassium channels to inhibit generation of action potentials.

Mechanically sensitive $\mathrm{A} \beta-, \mathrm{A} \delta$-, and $\mathrm{C}$-fibers in skin were present in normal proportions in the absence of TRPA1, suggesting that TRPA1 is not required for the general development and survival of these fibers. In addition, the fact that subclasses of rapidly and slowly adapting $A \beta$ - and $\mathrm{A} \delta$-fibers were present in the expected proportions indicates that TRPA1 does not regulate the phenotypic class of cutaneous sensory neurons.

The reduced mechanical firing rate in $\mathrm{C}$ - and AM-nociceptors is consistent with the expression of TRPA1 by small- to medium-diameter nociceptive DRG neurons (Story et al., 2003; Bautista et al., 2005; Kobayashi et al., 2005; Nagata et al., 2005), which have fine-caliber unmyelinated or thinly myelinated fibers that can be distinguished by differential NF labeling (Fundin et al., 1997; Rice et al., 1997). Although TRPA1 expression in sensory fibers in skin was not previously documented, we were able to detect TRPA1 immunolabeling and PLAP expression in small-caliber axons within nerves as well as on some sensory endings in the epidermis. The number of TRPA1-positive endings in the epidermis may be an underestimate because of the difficulty of discerning them among TRPA1-expressing keratinocytes.

In contrast to previous studies that showed TRPA1 expression exclusively in small-diameter DRG neurons (Story et al., 2003; Kobayashi et al., 2005; Nagata et al.,

$f$ In epifluorescence images (three panels), NF-IR is present on small, medium, and large neurons that are also PLAP positive in Trpa ${ }^{+/-}$animals (small, medium, and large yellow arrows, respectively). Small PLAP-labeled neurons are also present that lack NF (small red arrow), as well as large PLAPnegative neurons that are NF-positive (green arrow). $\boldsymbol{g}$, Percentages of DRG neurons containing Trpa1 mRNA and PLAP immunoreactivity from each genotype of mice $(n=4$ mice for each genotype). $\boldsymbol{h}$, Size distribution of PLAP-positive neurons in Trpa ${ }^{-1-}$ and Trpa1 ${ }^{+/-}$DRGs. The open bars are proportions of all neurons in each size range. The solid bars are only those neurons with PLAP immunofluorescence rated from 3 to 5 on a scale of 1-5. Since no differences in PLAPpositive neurons in $\mathrm{Trpa}^{-1-}$ and Trpa ${ }^{+1-}$ mice were observed, the genotypes were combined for the histogram. $\boldsymbol{i}$, Size distribution of neurons expressing Trpa1 mRNA in Trpa ${ }^{+1+}$ and Trpa ${ }^{+1-}$ DRGs. The open bars are proportions of all neurons in each size range. The solid bars are only those neurons with Trpa 1 mRNA levels rated from 3 to 5 on a scale of 1-5. Since no differences in Trpa $1 \mathrm{mRNA}$-expressing neurons were observed in Trpa $1^{+/+}$and Trpa ${ }^{+/-}$mice, the genotypes were combined. Scale bar, $50 \mu \mathrm{m}$. 


\section{Glabrous Skin}
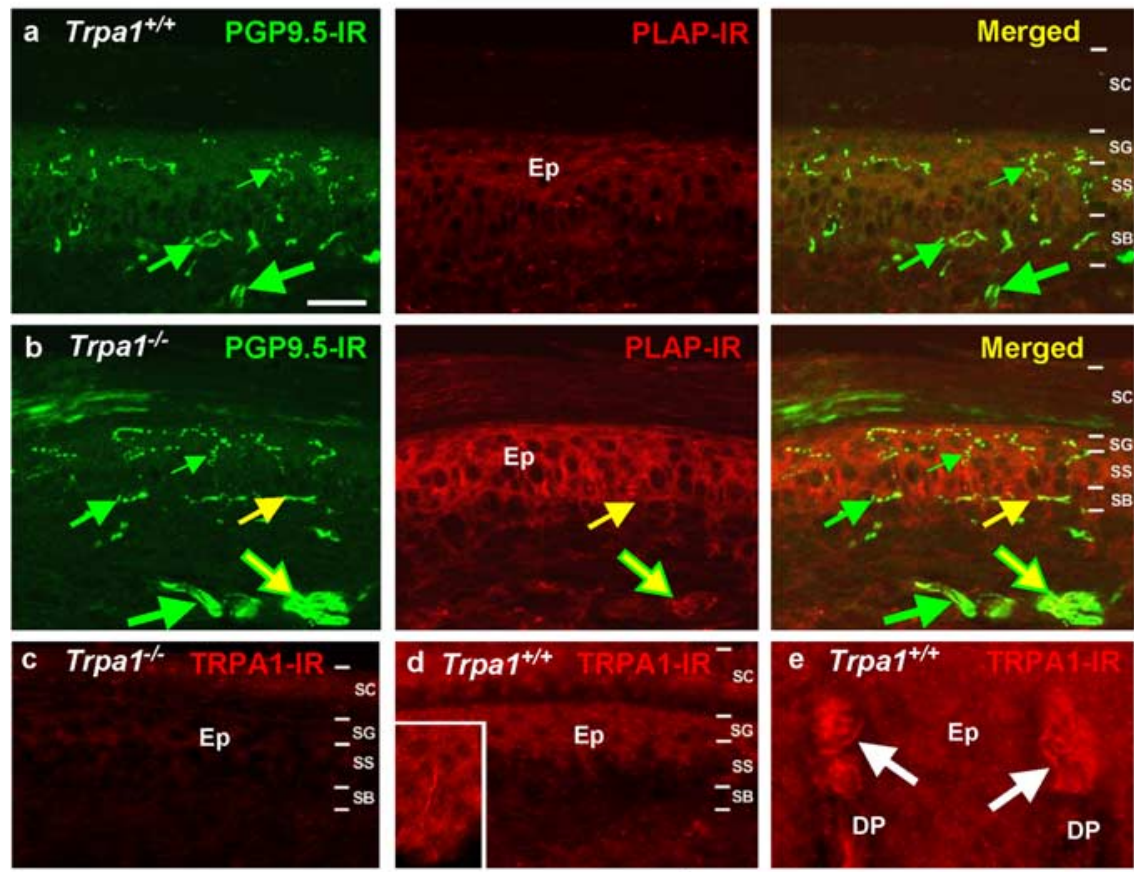

f

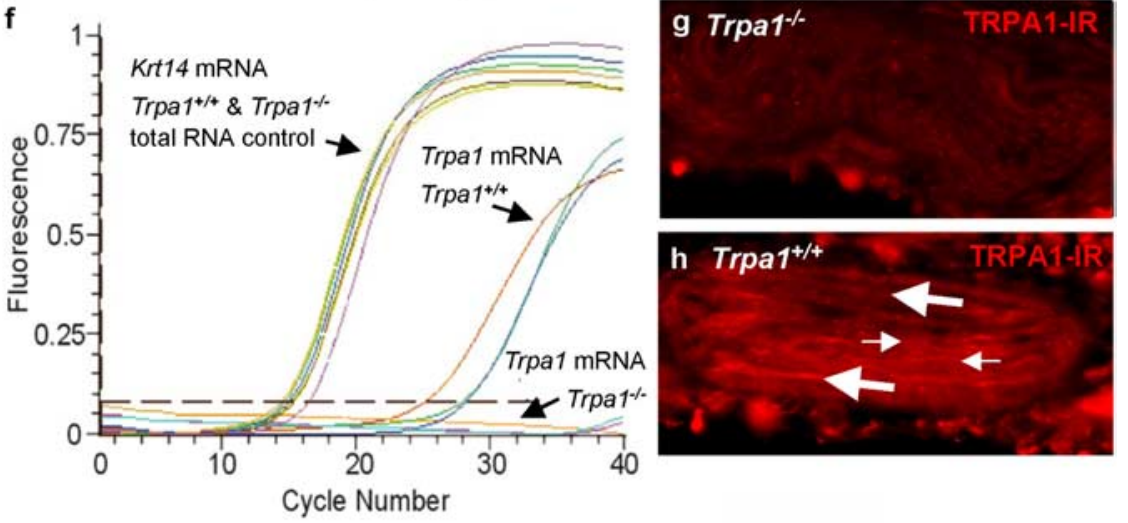

Figure 7. TRPA1 is normally present in keratinocytes of glabrous skin as well as on some intraepidermal endings and Meissner endings. Immunostaining of glabrous (nonhairy) hindpaw skin with PGP9.5, PLAP, and TRPA1 antibodies. Ep, Epidermis; DP, dermal papillae. $\boldsymbol{a}$, Double-label confocal images (three panels) of skin from $\operatorname{Trpa}^{+/+}$animals lacking the PLAP gene and stained for PGP9.5 and PLAP. Intraepidermal endings (small green arrows) and axons located just beneath the epidermis (medium green arrows) have PGP9.5 immunoreactivity (PGP9.5-IR) but no PLAP-IR. Some background fluorescence is present the epidermis (center panel). $\boldsymbol{b}$, Double-label confocal images (three panels) of skin from $\operatorname{Trpa1}^{-1-}$ animals having the PLAP gene and stained with PGP9.5 and PLAP antibodies. Sensory endings in the epidermis are only definitive for PGP9.5-IR (small green arrows). Some axons located just beneath the epidermis have only PGP9.5-IR (medium green arrows), whereas others are immunoreactive for both PGP9.5 and PLAP (medium yellow arrows). Nerves slightly deeper in the dermis have axons that are PLAP-positive and -negative (large yellow-green arrows). Keratinocytes are intensely labeled for PLAP in all live epidermal layers: stratum basalis (SB), stratum spinosum (SS), and stratum granulosum (SG). No PLAP is detectable in the dead keratinocytes of stratum corneum (SC). c, In an epifluorescence image, TRPA1 antibody does not label keratinocytes or innervation in this location in Trpa $1^{-1-}$ mice. $\boldsymbol{d}$, In an epifluorescence image, TRPA1-IR is present in live and dead layers of keratinocytes in $T r p a 1^{+/+}$mice. However, TRPA1-IR is lacking in SB. Occasional sensory endings in the epidermis are clearly TRPA1-immunoreactive ( $2 \times$ magnification inset). $\boldsymbol{e}$, In an epifluorescence image, sensory endings in Meissner corpuscles (white arrows), located in dermal papillae, have TRPA1-IR that is more intense than the TRPA1-IR in the keratinocytes of the adjacent epidermis. $\boldsymbol{f}$, Real-time PCR traces of total RNA from three different samples of glabrous skin obtained from Trpa1 ${ }^{+/+}$or $\operatorname{Trpa1}^{-1-}$ animals. Trpa1 mRNA levels were normalized using cytokeratin 14 (Krt 14) transcript levels to show the presence of Trpa1 transcript in wild-type but not in mutant animals. $\boldsymbol{g}$, In an epifluorescence image, the TRPA1 antibody fails to label axons in nerves deep in the dermis of Trpa ${ }^{-1-}$ animals. $\boldsymbol{h}$, In an epifluorescence image, TRPA1 antibody labels small- (small arrows) and large-caliber axons (large arrows) in nerves deep in the dermis of $\operatorname{Trpa}^{+/+}$animals. Scale bar, $25 \mu \mathrm{m}$.

2005), we also found TRPA1 in many medium to large DRG somata, and on large-caliber axons within nerves. Evidence for large-diameter, TRPA1-positive DRGs include a PLAP reporter controlled by the endogenous Trpa1 promoter, in situ hybridiza- tion for Trpal mRNA, and immunoreactivity for TRPA1 protein, all of which were controlled for by using tissue from wildtype, heterozygote, and mutant littermates. TRPA1 expression in large-diameter DRG neurons is further supported by large-caliber axon labeling, labeling of known anatomical types of $\mathrm{A} \beta$-fiber endings (lanceolate and Meissner corpuscles), and altered electrophysiological properties in $\mathrm{A} \beta$-fibers. In addition to cell-autonomous effects, adjacent cellular structures expressing TRPA1 could alter the mechanical firing properties of these sensory fibers.

Although we were unable to definitively detect TRPA1 in Merkel cells or Merkel endings, which are regarded as part of the lowthreshold SA A $\beta$ mechanoreceptive complex, the mechanical firing rate of this class of fibers was decreased. Since Merkel cells are embedded among TRPA1-expressing keratinocytes, it makes it difficult to assess their independent TRPA1 expression status. Conceivably, the impact of TRPA1 on Merkel cell innervation may be indirectly mediated via the keratinocytes.

Lanceolate nerve endings affiliated with hair follicles and Meissner corpuscles in dermal papillae were TRPA1-positive and are regarded as low-threshold RA A $\beta$ fiber mechanoreceptors. Both types of endings also lie in close proximity to TRPA1-expressing keratinocytes in the hair follicles and epidermis. Conceivably, some discrepancies between studies may be attributable to differences among species or to the sensitivity of detection using different methods.

Indeed, we found that keratinocytes in the epidermis of both hairy and glabrous skin from the hindpaw express TRPA1. The close spatial apposition of fine nerve terminals and keratinocytes suggests that these two cell types may interact in mediating mechanotransduction. Keratinocytes also express other TRP channels, including TRPV3, TRPV4, and TRPV1, which respond directly to heat and are thought to communicate with the terminals of sensory fibers (Peier et al., 2002b; Chung et al., 2004; Lee and Caterina, 2005). Thus, a plausible explanation is that TRPA1 activation in keratinocytes modulates the response properties of the nearby terminals of slowly and rapidly adapting $A \beta$ fibers and D-hair receptors.

The involvement of TRPA1 in sensing pungent compounds or endogenous neurotransmitters related to pain sensation has been well established (Bandell et al., 2004; Jordt et al., 2004; Bautista et al., 2006). However, its role in sensing mechanical stimuli is less clear. Here, we describe a modulatory role for TRPA1 in regulating mechanical firing, and this 
modulation may occur both in primary sensory neurons and in keratinocytes of the epidermis. Understanding how TRPA1expressing keratinocytes and primary afferent endings interact during somatosensation will assist in generating pharmacological reagents that block TRPA1 function to reduce mechanosensitivity without inducing complete loss of mechanical pain sensation.

\section{References}

Bandell M, Story GM, Hwang SW, Viswanath V, Eid SR, Petrus MJ, Earley TJ, Patapoutian A (2004) Noxious cold ion channel TRPA1 is activated by pungent compounds and bradykinin. Neuron 41:849-857.

Bautista DM, Movahed P, Hinman A, Axelsson HE, Sterner O, Högestätt ED, Julius D, Jordt SE, Zygmunt PM (2005) Pungent products from garlic activate the sensory ion channel TRPA1. Proc Natl Acad Sci US A 102:12248-12252.

Bautista DM, Jordt SE, Nikai T, Tsuruda PR, Read AJ, Poblete J, Yamoah EN, Basbaum AI, Julius D (2006) TRPA1 mediates the inflammatory actions of environmental irritants and proalgesic agents. Cell 124:1269-1282.

Bautista DM, Siemens J, Glazer JM, Tsuruda PR, Basbaum AI, Stucky CL, Jordt SE, Julius D (2007) The menthol receptor TRPM8 is the principal detector of environmental cold. Nature 448:204-208.

Cannon KE, Chazot PL, Hann V, Shenton F, Hough LB, Rice FL (2007) Immunohistochemical localization of histamine $\mathrm{H} 3$ receptors in rodent skin, dorsal root ganglia, superior cervical ganglia, and spinal cord: potential antinociceptive targets. Pain 129:76-92.

Caterina MJ, Leffler A, Malmberg AB, Martin WJ, Trafton J, Petersen-Zeitz KR, Koltzenburg M, Basbaum AI, Julius D (2000) Impaired nociception and pain sensation in mice lacking the capsaicin receptor. Science 288:306-313.

Chung MK, Lee H, Mizuno A, Suzuki M, Caterina MJ (2004) TRPV3 and TRPV4 mediate warmth-evoked currents in primary mouse keratinocytes. J Biol Chem 279:21569-21575.

Corey DP, García-Añoveros J, Holt JR, Kwan KY, Lin SY, Vollrath MA, Amalfitano A, Cheung EL, Derfler BH, Duggan A, Géléoc GS, Gray PA, Hoffman MP, Rehm HL, Tamasauskas D, Zhang DS (2004) TRPAl is a candidate for the mechanosensitive transduction channel of vertebrate hair cells. Nature 432:723-730.

Davis KD, Pope GE (2002) Noxious cold evokes multiple sensations with distinct time courses. Pain 98:179-185.

Djouhri L, Lawson SN (2004) Abeta-fiber nociceptive primary afferent neurons: a review of incidence and properties in relation to other afferent A-fiber neurons in mammals. Brain Res Brain Res Rev 46:131-145.

Doerner JF, Gisselmann G, Hatt H, Wetzel CH (2007) Transient receptor potential channel A1 is directly gated by calcium ions. J Biol Chem 282:13180-13189.

Fundin BT, Arvidsson J, Aldskogius H, Johansson O, Rice SN, Rice FL (1997) Comprehensive immunofluorescence and lectin binding anal-

\section{Hairy Skin}
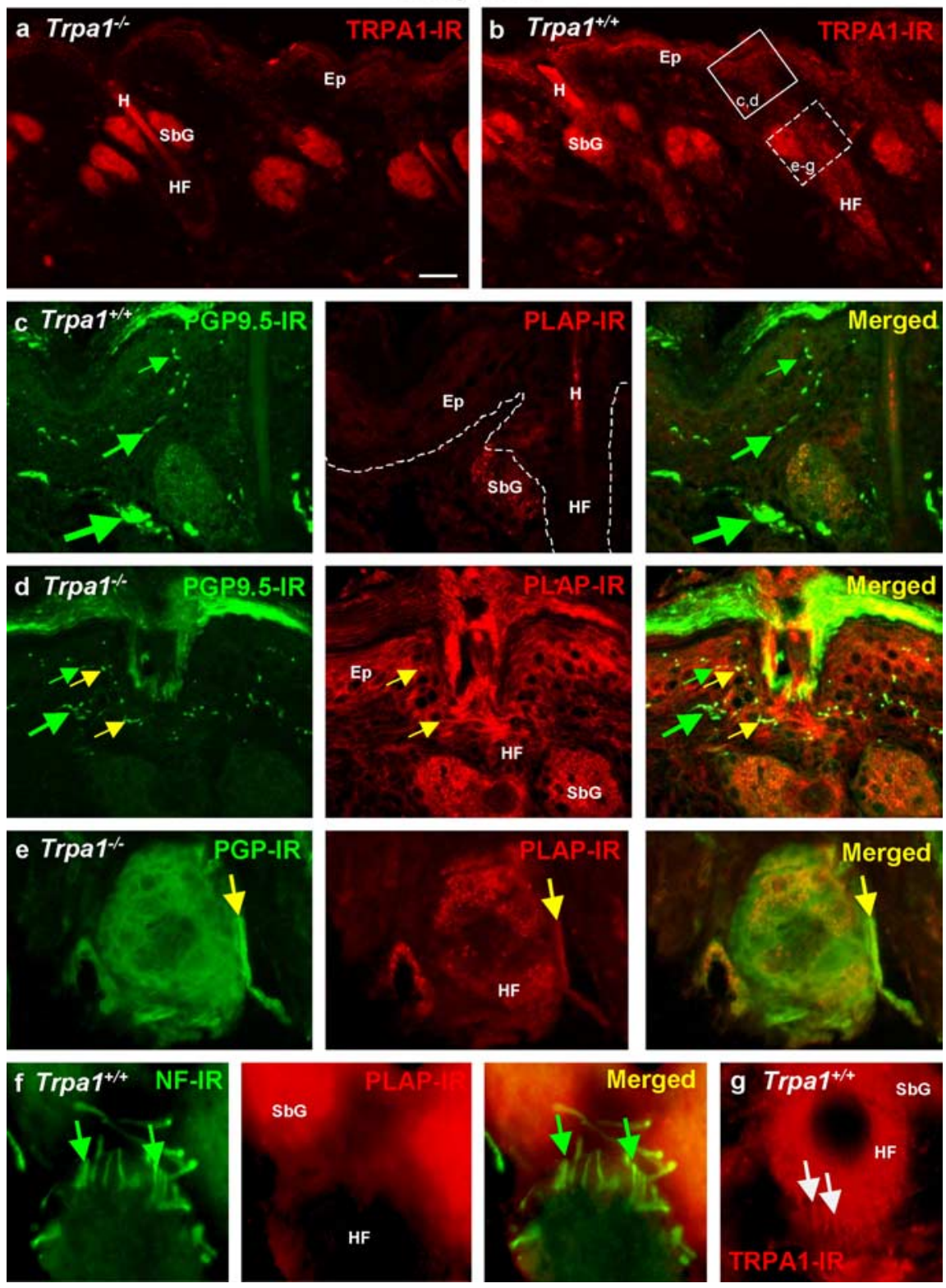

Figure 8. TRPA1 is normally expressed in epidermal and hair follicle keratinocytes, in some intraepidermal endings, and in lanceolate endings in hairy skin. $\boldsymbol{a}, \boldsymbol{b}$, Epifluorescent images of TRPA 1 immunoreactivity of hairy skin taken from the dorsal medial portion of the hindpaw in $\operatorname{Trpa}^{-1-}(\boldsymbol{a})$ and $\operatorname{Trpa}^{+/+}$mice (b). Ep, Epidermis; H, hair; HF, hair follicle; SbG, sebaceous glands; TRPA1 immunolabeling is present in keratinocytes throughout the epidermis and the hair follicles only in the wild-type mice. Autofluorescence is present in sebaceous glands and in hair shafts in the $\mathrm{Trpa}^{-1-}$ mice, whereas the fluorescence is much higher after TRPA1 labeling in Trpa $1^{+/+}$mice. The solid line square in $\boldsymbol{b}$ indicates the location of the enlarged images shown in $\boldsymbol{c}$ and $\boldsymbol{d}$. The broken line square indicates the location of the enlarged images shown in $\boldsymbol{e}-\boldsymbol{g}$. Hair follicles have autofluorescence. $\boldsymbol{c}$, Confocal images of PGP9.5 immunoreactivity (PGP9.5-IR) (left and right panels) reveal endings in the epidermis, at the epidermal border and deeper in the dermis (small, medium, and large green arrows) in $\mathrm{Trpa}^{+/+}$animals. PLAP immunolabeling is lacking in the innervation and keratinocytes (center panel). The broken line indicates the border of the epidermis and hair follicle where a basement membrane will be located. $\boldsymbol{d}$, Confocal images of PGP9.5-IR (left and right panels) reveal endings in the epidermis and at the epidermal border (small and medium arrows) in Trpa ${ }^{-1-}$ animals. Intense PLAP-immunolabeling is present in keratinocytes and the sebaceous gland (center and right panels). However, some PLAP-IR aligns uniquely with PGP9.5-labeled endings in the epidermis (yellow arrows), whereas other innervation is labeled only for PGP9.5 (green arrows). $\boldsymbol{e}$, In epifluorescence images, both PGP9.5-IR and PLAP-IR (three panels) are detected in Trpa ${ }^{-1-}$ mice on a lanceolate ending (yellow arrows) located parallel to the basement membrane of a hair follicle. Keratinocytes in the hair follicle also express PLAP-IR and label with anti-NF. $\boldsymbol{f}$, In epifluorescent images, lanceolate endings, which also normally express NF-IR (left and right panels, green arrows), lack PLAP-IR (center and right panels) in $T r p a 1^{+/+}$mice. The sebaceous glands have autofluorescence. $\boldsymbol{g}$, In an epifluorescence image, lanceolate endings (white arrows) and hair follicle keratinocytes in Trpa ${ }^{+/+}$mice label with TRPA1 antibodies. Scale bar, $100 \mu \mathrm{m}$. 
ysis of intervibrissal fur innervation in the mystacial pad of the rat. J Comp Neurol 385:185-206.

Howard J, Bechstedt S (2004) Hypothesis: a helix of ankyrin repeats of the NOMPC-TRP ion channel is the gating spring of mechanoreceptors. Curr Biol 14:R224-R226.

Jones RC 3rd, Xu L, Gebhart GF (2005) The mechanosensitivity of mouse colon afferent fibers and their sensitization by inflammatory mediators require transient receptor potential vanilloid 1 and acid-sensing ion channel 3. J Neurosci 25:10981-10989.

Jordt SE, Bautista DM, Chuang HH, McKemy DD, Zygmunt PM, Högestätt ED, Meng ID, Julius D (2004) Mustard oils and cannabinoids excite sensory nerve fibres through the TRP channel ANKTM1. Nature 427:260-265.

Karashima Y, Talavera K, Everaerts W, Janssens A, Kwan KY, Vennekens R, Nilius B, Voets T (2009) TRPAl acts as a cold sensor in vitro and in vivo. Proc Natl Acad Sci U S A 106:1273-1278.

Katsura H, Obata K, Mizushima T, Yamanaka H, Kobayashi K, Dai Y, Fukuoka T, Tokunaga A, Sakagami M, Noguchi K (2006) Antisense knock down of TRPA1, but not TRPM8, alleviates cold hyperalgesia after spinal nerve ligation in rats. Exp Neurol 200:112-123.

Kindt KS, Viswanath V, Macpherson L, Quast K, Hu H, Patapoutian A, Schafer WR (2007) Caenorhabditis elegans TRPA-1 functions in mechanosensation. Nat Neurosci 10:568-577.

Kobayashi K, Fukuoka T, Obata K, Yamanaka H, Dai Y, Tokunaga A, Noguchi K (2005) Distinct expression of TRPM8, TRPA1, and TRPV1 mRNAs in rat primary afferent neurons with adelta/c-fibers and colocalization with trk receptors. J Comp Neurol 493:596-606.

Koltzenburg M, Stucky CL, Lewin GR (1997) Receptive properties of mouse sensory neurons innervating hairy skin. J Neurophysiol 78:1841-1850.

Kress M, Koltzenburg M, Reeh PW, Handwerker HO (1992) Responsiveness and functional attributes of electrically localized terminals of cutaneous C-fibers in vivo and in vitro. J Neurophysiol 68:581-595.

Kwan KY, Allchorne AJ, Vollrath MA, Christensen AP, Zhang DS, Woolf CJ, Corey DP (2006) TRPA1 contributes to cold, mechanical, and chemical nociception but is not essential for hair-cell transduction. Neuron 50:277-289.

Lee H, Caterina MJ (2005) TRPV channels as thermosensory receptors in epithelial cells. Pflugers Arch 451:160-167.

Liedtke W, Friedman JM (2003) Abnormal osmotic regulation in trpv4 ${ }^{-1-}$ mice. Proc Natl Acad Sci U S A 100:13698-13703.

Lishko PV, Procko E, Jin X, Phelps CB, Gaudet R (2007) The ankyrin repeats of TRPV1 bind multiple ligands and modulate channel sensitivity. Neuron 54:905-918.

Macpherson LJ, Geierstanger BH, Viswanath V, Bandell M, Eid SR, Hwang S, Patapoutian A (2005) The pungency of garlic: activation of TRPA1 and TRPV1 in response to allicin. Curr Biol 15:929-934.

McKemy DD, Neuhausser WM, Julius D (2002) Identification of a cold receptor reveals a general role for TRP channels in thermosensation. $\mathrm{Na}-$ ture 416:52-58.

Mogil JS, Breese NM, Witty MF, Ritchie J, Rainville ML, Ase A, Abbadi N, Stucky CL, Séguéla P (2005) Transgenic expression of a dominantnegative ASIC3 subunit leads to increased sensitivity to mechanical and inflammatory stimuli. J Neurosci 25:9893-9901.

Moqrich A, Hwang SW, Earley TJ, Petrus MJ, Murray AN, Spencer KS, Andahazy M, Story GM, Patapoutian A (2005) Impaired thermosensation in mice lacking TRPV3, a heat and camphor sensor in the skin. Science 307:1468-1472.

Nagata K, Duggan A, Kumar G, García-Añoveros J (2005) Nociceptor and hair cell transducer properties of TRPA1, a channel for pain and hearing. J Neurosci 25:4052-4061.

Obata K, Katsura H, Mizushima T, Yamanaka H, Kobayashi K, Dai Y, Fukuoka T, Tokunaga A, Tominaga M, Noguchi K (2005) TRPAl induced in sensory neurons contributes to cold hyperalgesia after inflammation and nerve injury. J Clin Invest 115:2393-2401.

Peier AM, Moqrich A, Hergarden AC, Reeve AJ, Andersson DA, Story GM, Earley TJ, Dragoni I, McIntyre P, Bevan S, Patapoutian A (2002a) A TRP channel that senses cold stimuli and menthol. Cell 108:705-715.

Peier AM, Reeve AJ, Andersson DA, Moqrich A, Earley TJ, Hergarden AC, Story GM, Colley S, Hogenesch JB, McIntyre P, Bevan S, Patapoutian A (2002b) A heat-sensitive TRP channel expressed in keratinocytes. Science 296:2046-2049.

Petrus M, Peier AM, Bandell M, Hwang SW, Huynh T, Olney N, Jegla T, Patapoutian A (2007) A role of TRPAl in mechanical hyperalgesia is revealed by pharmacological inhibition. Mol Pain 3:40.

Price MP, Lewin GR, McIlwrath SL, Cheng C, Xie J, Heppenstall PA, Stucky CL, Mannsfeldt AG, Brennan TJ, Drummond HA, Qiao J, Benson CJ, Tarr DE, Hrstka RF, Yang B, Williamson RA, Welsh MJ (2000) The mammalian sodium channel BNC1 is required for normal touch sensation. Nature 407:1007-1011.

Price MP, McIlwrath SL, Xie J, Cheng C, Qiao J, Tarr DE, Sluka KA, Brennan TJ, Lewin GR, Welsh MJ (2001) The DRASIC cation channel contributes to the detection of cutaneous touch and acid stimuli in mice. Neuron 32:1071-1083.

Rice FL, Fundin BT, Arvidsson J, Aldskogius H, Johansson O (1997) Comprehensive immunofluorescence and lectin binding analysis of vibrissal follicle sinus complex innervation in the mystacial pad of the rat. J Comp Neurol 385:149-184.

Sawada Y, Hosokawa H, Hori A, Matsumura K, Kobayashi S (2007) Cold sensitivity of recombinant TRPA1 channels. Brain Res 1160:39-46.

Sotomayor M, Corey DP, Schulten K (2005) In search of the hair-cell gating spring elastic properties of ankyrin and cadherin repeats. Structure 13:669-682.

Story GM, Peier AM, Reeve AJ, Eid SR, Mosbacher J, Hricik TR, Earley TJ, Hergarden AC, Andersson DA, Hwang SW, McIntyre P, Jegla T, Bevan S, Patapoutian A (2003) ANKTM1, a TRP-like channel expressed in nociceptive neurons, is activated by cold temperatures. Cell 112:819-829.

Stucky CL, Koltzenburg M, Schneider M, Engle MG, Albers KM, Davis BM (1999) Overexpression of nerve growth factor in skin selectively affects the survival and functional properties of nociceptors. J Neurosci 19:8509-8516.

Tracey WD Jr, Wilson RI, Laurent G, Benzer S (2003) Painless, a Drosophila gene essential for nociception. Cell 113:261-273.

Walker RG, Willingham AT, Zuker CS (2000) A Drosophila mechanosensory transduction channel. Science 287:2229-2234.

Wetzel C, Hu J, Riethmacher D, Benckendorff A, Harder L, Eilers A, Moshourab R, Kozlenkov A, Labuz D, Caspani O, Erdmann B, Machelska H, Heppenstall PA, Lewin GR (2007) A stomatin-domain protein essential for touch sensation in the mouse. Nature 445:206-209.

Zurborg S, Yurgionas B, Jira JA, Caspani O, Heppenstall PA (2007) Direct activation of the ion channel TRPA1 by $\mathrm{Ca}^{2+}$. Nat Neurosci 10:277-279. 